\title{
RADIOMETRIC INVESTIGATION OF WATER OF CRYSTALLIZATION, LIGHT FILTERS, AND STANDARD ABSORPTION BANDS
}

\author{
By W. W. Coblentz
}

\section{CONTENTS}

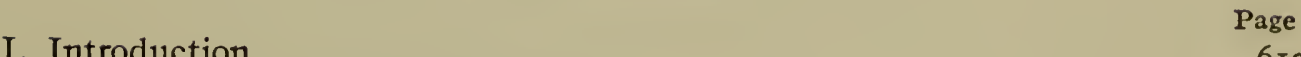

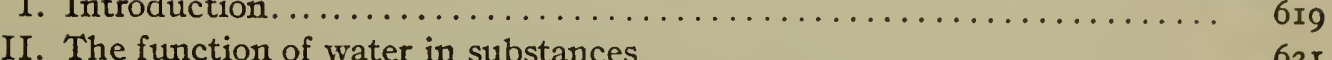

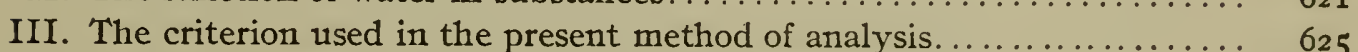

IV. The least thickness of water detectable radiometrically ............ 628

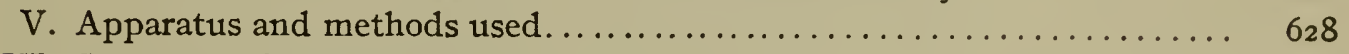

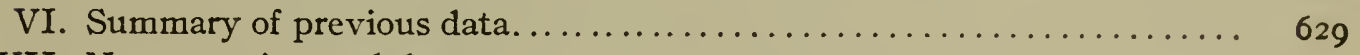

VII. New experimental data:

Group r.-Minerals containing water of crystallization......... 630

Group 2.-Minerals containing water of constitution............. 643

Group 3:-Miscellaneous substances................... 646

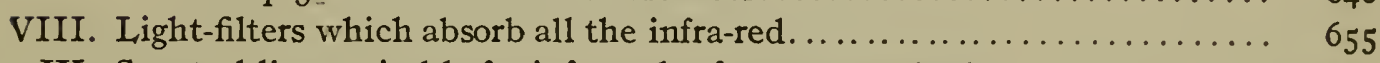

IX. Spectral lines suitable for infra-red reference standards........... $66 \mathrm{I}$

\section{INTRODUCTION}

Although investigations of infra-red absorption spectra were begun about 25 years ago, it was not until the first years of the present century that an attempt was made to systematize the data previously obtained, and to publish it, as well as new data, in standard wave lengths. This was due in part to the lack of knowledge of the optical constants (which precluded the calibration) of the prisms used and to the difficulty in operating the spectroradiometric apparatus. To some the data seemed to be of interest, but of no great utilitarian value. To others the data seemed useless because of the question of the purity of the material used and because of their not recognizing that the absorption spectrum of the impurity will be weak and will be superposed upon that of the substance in question. 
The early experimenters were at variance as to whether the cause of the absorption bands is an inter- or intra-molecular phenomenon. If the cause is intra-molecular, then it ought to be possible to identify certain characteristic absorption bands with specific groups of atoms or radicals in the compound under investigation. Now, in the study of the carbon compounds their constitution has been established by the replacement of certain constituents by organic radicals, by the preparation of a series of derivatives, by vapor density determinations, or by studying their physical properties in solution. Hence, following the example of the preceding experimenters, the writer turned to organic compounds for examples of substances having characteristic groups of atoms. Searching for further illustrations, groups of inorganic substances (e. g., sulphates and nitrates) were examined. The chemical formulæ of minerals appeared to be written with such exactness that this seemed a rich field for material. But it was soon found that in mineralogy it has as yet not been possible to apply any of the aforesaid methods used in organic chemistry, that the constitution of many minerals has been derived indirectly from analogies with other compounds which are better understood, and that in many cases the constitutional formulæ are in doubt.

Being familiar with the older ideas in regard to the condition of water in crystals, it seemed easy to settle the question of intermolecular action in causing absorption bands, by investigating substances containing water of constitution and water of crystallization; but at the very beginning ${ }^{1}$ it was found that this particular subject was in a more hopeless state of confusion than all the rest.

In the meantime extensive investigations of all sorts of compounds proved conclusively that the important groups of elements, radicals, which are found in chemical compounds, have a definite effect upon radiant energy, especially upon low frequency or socalled infra-red radiation. This effect is manifested by intense absorption bands, the positions of which are characteristic of the radical or group of atoms causing these bands.

Hence as a result of the application of these facts it has come about that instead of turning to chemistry and to other branches

${ }^{1}$ Coblentz: Physical Review, 20, p. 252; 1905. 
of physics to obtain evidence to explain the phenomena observed when radiant energy is passed through or is reflected from a substance, the problem is reversed and these very phenomena are now applied to explain several conspicuous and intricate questions concerning the constitution of matter, and in particular the question of the manner in which water, or the constituents which form water, are combined in chemical compounds.

The investigation of water in minerals has been carried on at various times ${ }^{2}$ during the past six years. It consisted in but little more than gathering data and publishing it, leaving to the future the practical applications.

The interest which Dr. Hillebrand has taken in this method of analysis has served to renew my interest in it and to further test its possibilities. After due consideration of the problem it was deemed best to renew the work by investigating opals having different amounts of water, from 3 to 8 per cent. After beginning the work it was found possible to decrease the water content of, and even to completely dehydrate, some specimens without seriously impairing their homogeneity. The material was selected from the collection in the United States National Museum. The water content was very kindly determined by Dr. Hillebrand, after which the cutting of the sections was done by the United States Geological Survey.

\section{THE FUNCTION OF WATER IN SUBSTANCES}

The manner in which water of crystallization is held in minerals is not understood. By some it is considered to belong to the molecular structure; by others it is held that the molecules of water belong only to the crystalline structure. It is a characteristic of water of crystallization that it is expelled from a mineral by very gentle ignition, always at a temperature far below red heat and frequently below $100^{\circ} \mathrm{C}$.

In the case of water of constitution, the water is not supposed to exist as such in the mineral, but to result from the union of

${ }^{2}$ Water of Constitution and Water of Crystallization, Phys. Rev., 20, p. 252; 1905. Phys. Rev., 23, p. 125; 1906. This Bulletin, 2, p. 457; 1907. Jahrbuch f. Radioaktivität und Electronik, 3, p. 397; I907. Phys. Rev., 30, p. 322; Ig1o. Publication No. 65 , Carnegie Institution of Washington. 
oxygen and hydrogen or from hydroxyl groups contained in the molecule. It is characteristic of this class of substances that they must be strongly heated, sometimes to a white heat, before they are decomposed and all the water is expelled.

The earlier writers held that in the case of crystalline substances the molecules of water exist in their entirety, situated among the other molecules of the substance, whence the name water of crystallization.

"The compounds ${ }^{3}$ containing water of crystallization are usually denied the title of atomic compounds, ordinarily applied to combinations of two or more elements in which the constituent atoms are associated in a single molecule, under the influence of the force which has received the name of chemical affinity, and in contradistinction are termed molecular compounds, being regarded as combinations of two or more separate molecules, e. g., $\mathrm{CaSO}_{4}+2 \mathrm{H}_{2} \mathrm{O}$. This, although perhaps true of many compounds containing water of crystallization, is certainly not true of all, and notably of some of the sulphates (e. g., $\mathrm{MgSO}_{4}+7 \mathrm{H}_{2} \mathrm{O}$ ), which are deprived of their water of crystallization by heating to a high temperature. The last molecule retained with such persistency was termed water of constitution to distinguish it from water of crystallization.

In the present state of our knowledge it is impossible absolutely to define the meaning of these terms, or even to say that there is an absolute difference between the so-called water of crystallization and water of constitution, and not merely one of degree."

In many compounds the affinity seems different for the different parts of the crystal water. For example, ordinary alum $\mathrm{AlK}\left(\mathrm{SO}_{4}\right)_{2}+\mathrm{I}_{2} \mathrm{H}_{2} \mathrm{O}$ gives off five molecules of $\mathrm{H}_{2} \mathrm{O}$ at $100^{\circ}$, and five molecules at $\mathrm{I}^{2} 0^{\circ}$, while the last two molecules remain until heated to $200^{\circ}$. In the same manner in the sulphates of $\mathrm{Mg}$, $\left(\mathrm{MgSO}_{4}+{ }_{7} \mathrm{H}_{2} \mathrm{O}\right), \mathrm{Zn}, \mathrm{Fe}, \mathrm{Ni}$, and $\mathrm{Co}$ six molecules of water are given off at about $130^{\circ}$ while the last molecule of $\mathrm{H}_{2} \mathrm{O}$ does not pass off until heated to $200^{\circ}$ to $300^{\circ} \mathrm{C}$. Examples of water of constitution are mica, and brucite, $\mathrm{Mg}(\mathrm{OH})_{2}$, in which the $\mathrm{O}$ and

${ }^{3}$ Encyclopædia Britannica, 9th ed., V, pp. 489, 505. See also Graham-Otto Lehrbuch der Chemie, II, p. 173. 
$\mathrm{H}$ atoms are not united as $\mathrm{H}_{2} \mathrm{O}$, and do not unite to form water until sufficient heat is applied.

In cases where successive portions of water are given off at different temperatures it is difficult to make a distinction between water of crystallization and water of constitution. In the minerals just quoted it has been found that the heat of hydration of the last molecule of water is different from that of the molecules of water which pass off at a lower temperature, which confirms the belief of a difference in the bonding in the two cases.

Various other criteria have been set up (often based upon physical tests, refraction and polarization) by experimenters to distinguish between these various forms of water, but all seem unsatisfactory. For example, the fact that in certain crystals the water passes off at one, two, or three fixed temperatures, with a supposed change in homogeneity, has been considered evidence that the water is present as a definite compound. But the absorption and reflection bands of selenite $\left(\mathrm{CaSO}_{4}+2 \mathrm{H}_{2} \mathrm{O}\right)$ show that it is a "double salt" or "molecular compound;" for the spectrum of selenite is the composite of the spectra of anhydrite $\mathrm{CaSO}_{4}$, and of water, $\mathrm{H}_{2} \mathrm{O} .{ }^{4}$ If selenite were a new compound, formed by the union of water and $\mathrm{CaSO}_{4}$, then the (absorption and reflection) spectrum should be entirely different from that of the constituents, just as is true of mica. That some of these hypotheses are too limited is shown by the fact that the absorption spectra of various substances like selenite, opal, and the zeolites are identical as regards the position and intensity of the water bands. The water must therefore be present in the same manner in these two types of crystals; and since the absorption bands are identical with those of water in its free (liquid) state it would appear that the temperature fixed point and vapor pressure tests are not a sufficient criterion for judging this question. If the water were chemically combined in selenite, then one would expect to find the absorption bands of water to be absent. It would appear just as tenable to consider the water occluded under a definite pressure, which raises its boiling point to a higher temperature. [In this connection it would be interest-

4 This Bulletin, 2, p. 457; 1907. Carnegie Publication No. 65, pp. 18,77 , and 79 . 
ing to investigate the expansion, with change in temperature, of crystals containing water of crystallization, to learn whether there is a minimum such as obtains in water at $4^{\circ} \mathrm{C}$.] Or we may liken the crystal unto a block built up of bricks and mortar. This analogy can not extend very far, since an explanation is demanded why in the one case the cement (water) crumbles at a definite temperature while in other cases (zeolites) the phenomenon is progressive with rise in temperature.

That the hypothesis that water in crystals is united as a definite compound is based on a too narrow foundation is illustrated in the zeolites. They are crystalline compounds and the water is very loosely held. The water continues to be gradually expelled as the temperature is raised, and it may be replaced by other substances, such as $\mathrm{NH}_{3}, \mathrm{H}_{2} \mathrm{~S}$, or $\mathrm{C}_{2} \mathrm{H}_{5} \mathrm{OH}$. The dehydrated crystals absorb definite quantities of these substances as a sponge absorbs water, the process being accompanied by the evolution of heat. Since the amount of water present varies continuously with the vapor pressure, it is generally concluded that the water in the zeolites is not analogous to the water of crystallization of most hydrated salts, but resembles more nearly the intermixture which occurs in solid solution. In this case the hypothesis is tenable, for amorphous substances, e. g. opal, which have similar absorption spectra, are also considered solid solutions; and in both groups of minerals the absorption spectrum of the hydrated material is the composite of water and of the anhydrous substance. But the vapor pressure criterion is not sufficient to judge minerals as may be noticed from the experiments on tremolite. Here, too, the water is expelled gradually ${ }^{5}$ with rise in temperature and it was considered dissolved water; but no absorption bands of water are observable. The small bands at $2.9 \mu$ may be due to hydroxyl groups as inferred by Penfield and Stanley ${ }^{6}$; for in brucite $\mathrm{Mg}(\mathrm{OH})_{2}$, in diaspore, $\mathrm{AlO}(\mathrm{OH})$, and in göthite, $\mathrm{FeO}(\mathrm{OH})$ the $3 \mu$ band is very weak ${ }^{7}$, as is true of the band in tremolite.

\footnotetext{
${ }^{5}$ Allen and Clement: Amer. Jour. Sci., 26, p. ror; 1908.

${ }^{6}$ Penfield and Stanley: Amer. Jour. Sci., 23, p. 23; 1907.

${ }^{7}$ Publication No. 65, Carnegie Institution of Washington. This Bulletin, 2, p. $466 ; 1907$.
} 
Turning from the crystals (e. g. sulphates) which give off their water at one or more fixed temperatures to the zeolites, which are also crystalline substances, it is found as mentioned on a previous page, that in the latter group of minerals the water is given off gradually between $100^{\circ}$ and about $400^{\circ}$. To explain this phenomenon it is supposed that the water is not chemically combined, but is present as solid solution. On this hypothesis the water should be present as such, and should give the absorption bands of water. As a matter of fact, as already mentioned, the zeolites do show the absorption bands of water; but so do the sulphates and other substances in which the water is expelled at a fixed temperature, indicating the sameness of the water in both groups. It is not clear to the writer why, if in some substances the water may be expelled at one fixed temperature and in another substance at several fixed temperatures, it is not possible to have still other crystalline structures from which the water may be expelled at all temperature gradations; and yet have the water present in the same condition in all of them, as indicated by the radiometric tests.

\section{THE CRITERION USED IN THE PRESENT METHOD OF ANALYSIS}

The criterion used in the present investigation for judging the condition of water in compounds is based upon the evidence deduced from extensive experimental data which shows that the absorption spectrum of a compound is not the composite of the absorption bands of the constituent elements. In this case the "physical molecule" has been changed. On the other hand, if the molecules (or the groups of atoms which cause the characteristic absorption bands) undergo no physical change when they combine to form a crystal (e. g., selenite, $\mathrm{CaSO}_{4}+2 \mathrm{H}_{2} \mathrm{O}$ ) or when they enter into solution, then the absorption spectrum of the resultant combination will be the composite of the absorption bands of the constituents. Now this is the proposition that conflicts with some of the notions concerning definite chemical compounds. From the fact that there is a certain heat of hydration manifested in the formation of a crystalline substance, e. g., hydrous sulphates, it is inferred that there is a new compound 
formed, when as a inatter of fact the radiometric test shows that the water and the sulphate bands are just the same in magnitude and in position as they were before the constituents were united.

In judging the condition of water in minerals the main difficulty is in using substances which in the anhydrous state have no large absorption bands near the bands characteristic of water in its free, liquid, state. An excellent example is found in selenite, $\mathrm{CaSO}_{4}+$ $2 \mathrm{H}_{2} \mathrm{O}$, which has an unusually large absorption band at $4.6 \mu$. This seemed to throw doubt upon the adequacy of the radiometric test until after the examination of anhydrite, $\mathrm{CaSO}_{4}$, and other anhydrous sulphates, when it was shown that this large absorption band is characteristic of the sulphates. In the same manner the presence of $\mathrm{OH}$ groups in cane sugar confuses matters at $3 \mu$, so that the probability of cane sugar having a molecule of water of crystallization is based upon the evidence deduced from the presence of absorption bands at $I .5{ }^{\prime \prime}$ and $4.75 \mu$ which coincide with the water bands at these points. The evidence not being very strong in this case, the writer has never laid nuch stress upon it, in spite of the great similarity of the spectrum to that of other sugars having $\mathrm{H}_{2} \mathrm{O}$. In all the other examples previously described, the most superficial examination shows that the absorption bands of water in the various minerals are identical in magnitude and in position with those found in water in its free liquid state. Hence, in the present investigation, the criterion for distinguishing water of crystallization from water of constitution is the presence of absorption bands at $1.5,2,3,4.75$, and $6 \mu$ which is the location of the absorption bands of water. If there are no other absorption bands nearby, then the intensity of these bands will be found similar to those of water, viz., the bands at $\mathrm{I} .5,2$, and $4.75 \mu$ will be weak while the bands at $3 \mu$ and $6 \mu$ will be very strong. Hydroxyl groups cause an absorption band at $3 \mu$, hence not distinguishable when present with water. Furthermore, the evidence for $\mathrm{OH}$ groups is not so clear cut and definite as is found in water of crystallization. The intensity of the band seems to depend upon the activity of the $\mathrm{OH}$ group. For example, of the various hydroxides studied, the alcohols, etc., have a sharply defined 
band at $3 \mu$ while in brucite, $\operatorname{Mg}(\mathrm{OH})_{2}$, and in several other minerals, the band at $3 \mu$ is almost if not entirely wanting. In the alcohols, etc., the $\mathrm{OH}$ is more active since its hydrogen is replacable by a metal (more acid), than the $\mathrm{OH}$ in brucite which is not replacable (more basic). Whether this is the true explanation of the phenomenon remains undetermined; and since the question of $\mathrm{OH}$ groups is of secondary importance in the present work, it need not be given further attention at present.

In passing it is of interest to note that substances containing the $\mathrm{C}=\mathrm{O}$ group (aldehydes, ketones, acids, esters) have a very marked absorption band in the region of 5.8 to $5.9 \mu$. Silicates, as well as quartz, have a very small absorption band in the region of $2.9 \mu$, which is barely noticeable in the thin sections of minerals examined. Since the band is so weak, there is no danger of confusing it with the strong water band at $3 \mu$ in opals.

In contrast with the other criteria, the radiometric test of the condition of water in minerals gives far more consistent results in classifying certain minerals. It is to be noticed, however, that this method of analysis shows no distinction between water of crystallization, dissolved water, and water of solid solution. In its behavior toward radiant energy the molecule of water in crystals and in solid solution is identical with water in its free liquid state. This is, of course, in conflict with the commonly accepted notions concerning water of crystallization and water of solid solution; but it seems to be the only logical interpretation of the data obtained by the present method.

The main difficulty in this investigation is in obtaining substances which in the anhydrous state are free from absorption bands. This is practically impossible, since all substances have characteristic absorption spectra. Hence the best that one can do is to investigate various substances. Some give inconclusive evidence in one region of the spectrum, e. g., cane sugar at $3 \mu$, while others confuse matters further in the infra-red, e. g., the sulphates at $4.55 \mu$. Considered as a whole, however, the evidence is complete and convincing. 


\section{THE LEAST THICKNESS OF WATER DETECTABLE RADIOMETRICALLY}

This is about the first question asked in connection with the methods used in the present investigation.

On a subsequent page it will be shown that a given layer of water vapor is far more transparent than the same column when condensed into a liquid film, although the large absorption bands are found in both the liquid and in the vapor phase, the only difference being that of intensity. The film of water which is found on rock salt (prisms) does not cause absorption bands.

Whether the absorption bands of water are absent in substances which are more hydroscopic than rock salt (or in rock salt itself when exposed to very humid air) has not been determined. Furthermore, it must be shown that such a film of water is continuous.

It will be shown presently (see Figs. 6 and 7) that after dehydrating a certain sample of opal it absorbed water at the rate of about 0.06 per cent (see Fig. 7, B) per day. The various transmission curves are so widely separated that an increase in the water content amounting to one-third to one-fourth this value (or 0.02 per cent) could easily have been detected. The thickness of the section of opal was $0.105 \mathrm{~mm}$; and if 0.02 per cent of it is water the equivalent layer of water, if concentrated into a liquid film, would be about $3 / 100,000 \mathrm{~mm}$ in thickness.

\section{APPARATUS AND METHODS USED}

The apparatus used in the present investigation is essentially the same as used in previous work. The spectrum was produced by means of a $60^{\circ}$ fluorite prism mounted on a spectrometer made of silvered mirrors $50 \mathrm{~cm}$ in focal length. The spectrum was explored by means of a very sensitive vacuum bolometer, which is now being used in all radiation work requiring high precision. The complete period of the auxiliary galvanometer was only 4 seconds, which means a great saving in time when one considers that in some of the earlier work I to I.5 minutes were required to make a single observation. The spectrometer slit and the width of the bolometer were $0.6 \mathrm{~mm}$ wide or $4^{\prime}$ arc. A Nernst glower was used as a source of energy. An image of the glower was projected upon 
the spectrometer slit by means of a $15-\mathrm{cm}$ focal length silvered mirror. The crystal section was mounted in a holder directly in front of the spectrometer slit. The methods of observation consisted in (I) noting the galvanometer deflection when the crystal section was in the path of the light from the glower, and (2) noting the galvanometer deflection when the crystal section was not before the spectrometer slit. The ratio of $(\mathrm{I}) \div(2)$ gives the transmission in any given part of the spectrum, and it is simply a matter of setting the bolometer in different parts of the spectrum and noting the two galvanometer deflections. The method is analogous to spectrophotometric measurements, the bolometer being substituted for the eye. An accuracy of I part in 200 to 400 is easily attainable, which is more precise than is required.

The mineral sections were ground thin but not highly polished. The size of the specimens was about 8 by $15 \mathrm{~mm}$. They were mounted upon thick cardboard having rectangular openings cut therein. In this manner no light reached the spectrometer slit, except that which passed through the mineral section.

For further details in regard to apparatus and methods of observation the reader is referred to previous investigations of a similar nature: ${ }^{8}$

\section{SUMMARY OF PREVIOUS DATA}

In previous investigations of at least 34 substances, said to contain "water of crystallization," the one exception (aside from tremolite which is included in the present paper) to the rule that such substances show the absorption bands of water was brucine, $\mathrm{C}_{23} \mathrm{H}_{26} \mathrm{~N}_{2} \mathrm{O}_{4}+4 \mathrm{H}_{2} \mathrm{O}$, which is an alkaloid having a complicated and unknown structure. An extensive examination of this compound failed to reveal any absorption bands of water. The transmission curve ${ }^{9}$ has sharp bands at $1.7,3.43,6.86$, and $7.3 \mu$ which are to be found in all substances containing $\mathrm{CH}_{2}$ and $\mathrm{CH}_{3}$ groups. It has also a very large band at $5.95 \mu$ (and $8.3 \mu$ ) which is to be found in all substances containing the $\mathrm{C}=\mathrm{O}$ group. It is

8 Physical Rev., 16, p. 35; I903. Publication, Carnegie Institution No. 35, I905; No. 97 , I908. This Bulletin, 4, p. 392; 1907 .

${ }^{9}$ Publication No. 65 , p. 40, Carnegie Institution of Washington. 
quite transparent throughout the infra-red. It is supposed to contain I 6 per cent of crystal water which would be sufficient to cause a far greater opacity than was observed radiometrically.

The list of minerals containing water of constitution included about a dozen samples of hydroxides ( $\mathrm{OH}$ groups). As stated elsewhere, the absorption band of $\mathrm{OH}$ groups, which is so characteristic of alcohols at $3 \mu$, is often very weak and sometimes it is entirely unresolved by the spectroscope. In serpentine there is a band at $3 \mu$ which is very strong, and confirms the view that there are hydroxyl groups present in this mineral. The radiometric analysis also confirmed the view ${ }^{10}$ that there are no hydroxyl groups in talc, in which there is not even a trace of an absorption band at $3 \mu$.

The one exception to the other methods of classifying the 28 substances examined, containing water of constitution, was cane sugar which is not supposed to have water of crystallization. As mentioned on a previous page, the evidence is not very strong; but there is sufficient similarity between the transmission spectrum of cane sugar and of other sugars having water of crystallization (no similarity with fructose which has no crystal water) to suggest the presence of a molecule of water of crystallization.

It seems rather remarkable that out of a sum total of more than 60 substances examined radiometrically only two (perhaps only one) were found which did not agree with the other classification into water of crystallization and water of constitution.

\section{NEW EXPERIMENTAL DATA}

\section{GROUP 1. MINERALS CONTAINING WATER OF CRYSTALLIZATION}

Under this heading are described the characteristics of several crystalline and amorphous substances containing water. For, as already mentioned, the radiometric test finds no distinction between water of crystallization, absorbed water, or water in solid solution.

Water, $\mathrm{H}_{2} \mathrm{O}$.- - In order to appreciate fully the significance of the data to be presented on minerals, it is necessary to describe the characteristics of water when examined in the liquid and in the

${ }^{10}$ Clarke and Schneider: Amer. Jour. Sci., 40, p. 308; 1890. 


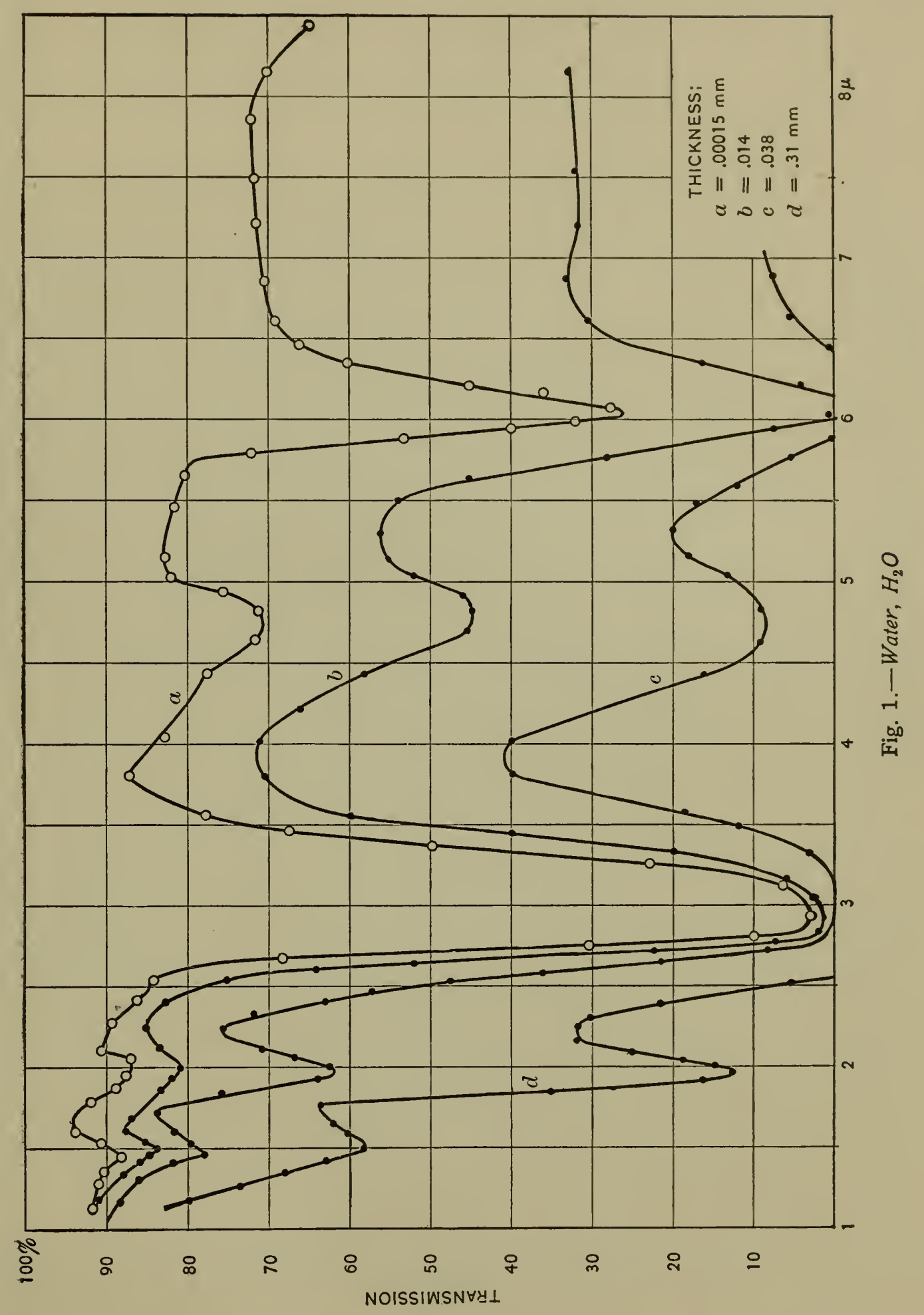


vapor state. All observers ${ }^{11}$ agree in their location of large absorption bands of water at the approximate wave lengths $1.5,2$, 3, 4.75 , and $6 \mu$ All have found that water is extremely opaque to the deep infra-red radiation, so that the film had to be reduced to a few thousandths of a millimeter in thickness in order to be able to study it at all.

In fact, of all the substances examined, which includes all the great groups of chemically related compounds, water stands unique in having a spectrum of numerous narrow absorption bands, which can be resolved only when the substance is reduced to a highly attenuated vapor. In the liquid state these groups of small bands coalesce into large bands as indicated in figure $\mathrm{I}$. It is of course well known that a very thick layer of water is required to produce absorption in the visible spectrum. ${ }^{12}$ The same is true for the infra-red region out to $0.933 \mu$ (the " $\rho$ " band in Fig. 2) but beyond this point the "general absorption" increases very rapidly, so that a layer of water $\mathrm{I} \mathrm{cm}$ in thickness absorbs all frequencies beyond $1.4 \mu$, and a layer $0.5 \mathrm{~mm}$ in thickness causes complete opacity beyond $2 \mu$. The absorption of water for heat waves longer than $5 \mu$ is so much greater than at $2 \mu$ that a layer only o.r mm in thickness causes complete opacity beyond $5 \mu$. Beyond $8 \mu$ to about $50 \mu$ water is quite transparent, having no large absorption bands which would be useful in investigating the present problem.

The transmission curves of various thicknesses of water ( $a=0.00015 \mathrm{~mm} ; b=0.014 \mathrm{~mm} ; c=0.038 \mathrm{~mm} ; d=0.3 \mathrm{Imm}$ ) are given in figure $\mathrm{I}$. The cell, containing water, was made of two large, clear fluorite plates separated by tinfoil. The various thicknesses were obtained by varying the number of layers of tinfoil. For curve $a$, the thinnest obtainable platinum, used in making bolometers, was inserted between the fluorite plates. The thickness of the platinum was computed from the electrical resistance and the surface dimensions of a bolometer strip. These curves show the great opacity of water at $6 \mu$ as compared with the region of 1.5 and $2 \mu$.

${ }^{11}$ Julius: Verhandl. Königl. Akad. Amsterdam, Deel I, No. I, I892. Paschen: Ann. der Phys. (3), 53, p. 334; 1894. Aschkinass: Ann. der Phys. (3), 55, p. 406; 1905.

${ }^{12}$ Abney and Festing: Phil. Trans., 172, p. 887; 1882. Kayser: Spectroscopie, vols. 2 and 5 . 
Ångström ${ }^{13}$ has shown that water vapor is more transparent than the liquid phase, when in such layers that the thickness is inversely proportional to the density. A familiar example is atmospheric water vapor which transmits the sun's radiation ${ }^{14}$ to I $\mu$, while a layer of water 2.85 centimeters thick, which is equivalent to the

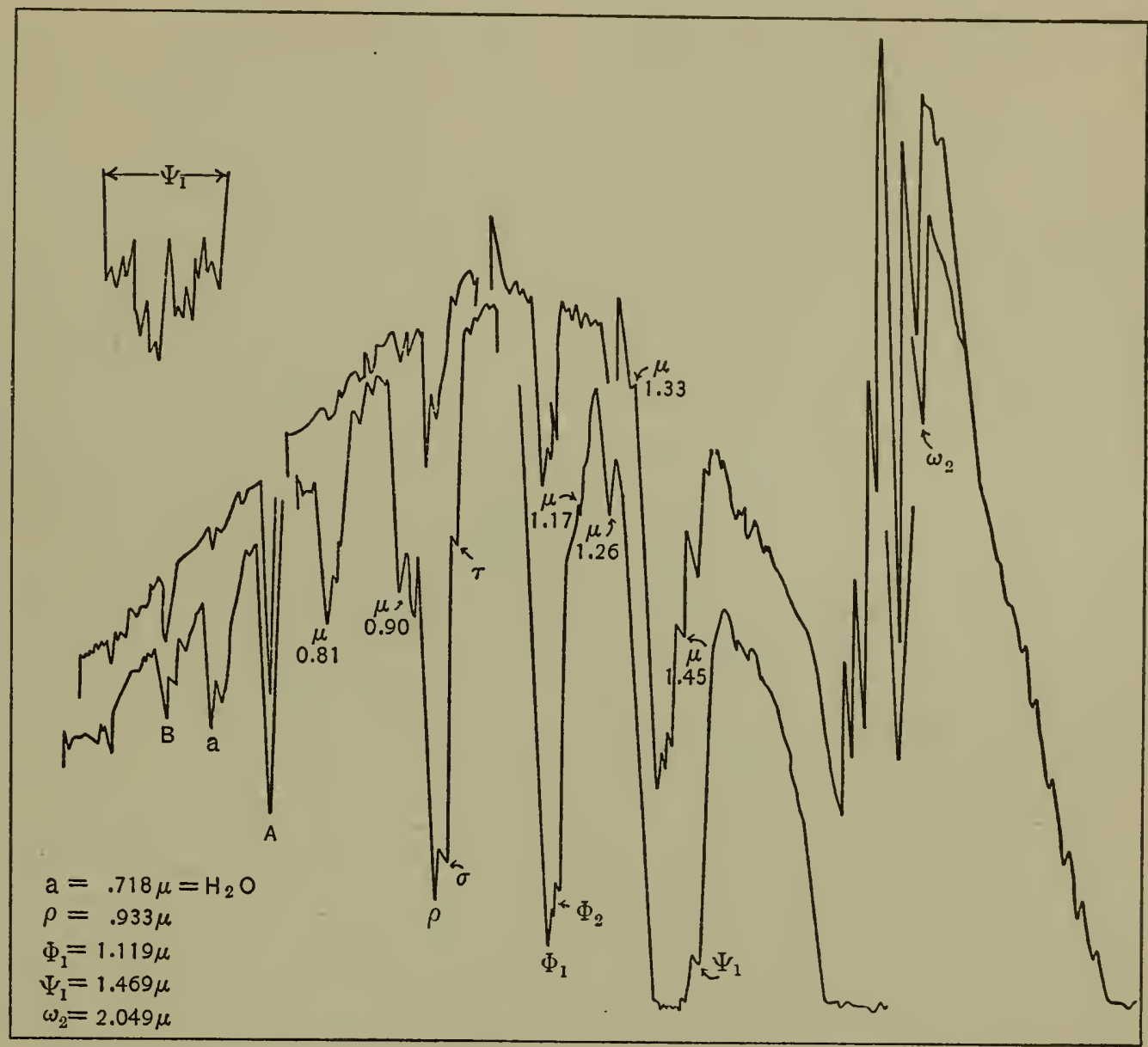

BOLOGRAPHIC ENERGY CURVES OF THE SOLAR SPECTRUM OF A $60^{\circ}$ GLASS PRISM

Fig. 2

water vapor in the earth's atmosphere (see Arihenius Lehrb. der Kosmischen Physik, p. 630) absorbs everything beyond I.2 The complexity of the absorption bands at $I .45 \mu$ and at $2 \mu$, in figure $I$, is shown in the spectrobolographic curves ${ }^{15}$ made at the

13 Ångström: Ann. der Phys. (3), 39, p. 267, 189o; (4) 6, p. I63, I9or.

${ }^{14}$ Langley: Nat. Acad. Sci., 4, pt. 2, p. 197. Discussion in Carnegie Publication No. 97 , p. 143 .

15 Fowle: Smithsonian Misc. Coll., vol. 47, No. I468; I904. 
Astrophysical Observatory. These curves are reproduced in figure 2. The upper curve, for February 19, 1903, was made when there was but small water-vapor absorption. The lower curve, for September 14, 1903, was made when the humidity was high, and hence there was great water-vapor absorption. The rapid variation in intensity of the absorption bands is analogous to the observations in figure I. A further illustration of the complexity of the water bands is given in figure 3 , which relates to the band at $6 \mu$ in figure $\mathrm{I}$. Curve $a$, figure 3 , was obtained by placing a Nernst glower at a distance of 4.2 meters from the spectrobolometer and projecting an image of the glower upon the spectrometer slit by means of a large concave mirror. The spectral energy curve was then observed in the usual manner. When plotted to scale as shown in curve $a$, figure 3 , the energy curve shows numerous indentations. The dotted line represents roughly the spectral energy curve of the glower if there were no absorption bands. By taking the ratio of the ordinates of the continuous part of curve $a$, to the dotted curve, at various wave lengths, curve $b$ is obtained. The latter represents very closely the transmission of 4.2 meters of air, which contains a layer of precipitable water equal to $0.02 \mathrm{~mm}$ in thickness. The water content was derived from the relative humidity $(=25$ per cent; room temperature $=21.7^{\circ}$ ) and the amount of water vapor per cubic meter. It is to be noticed that the $6 \mu$ band which shows complete opacity for a sinilar layer of liquid, curve $b$, figure $\mathrm{I}$, is resolved into at least six bands with maxima at 5.75, 5.9 I, 6.05, $6.15,6.4 \mathrm{I}$, and $6.56 \mu$. The short air column used, $4.2 \mathrm{~m}$, was not sufficient to show the absorption bands of water vapor at $3 \mu$.

Anhydrite, $\mathrm{CaSO}_{4}$. -The substance examined was a cleavage piece, split parallel to the $c$ axis; thickness $=0.656 \mathrm{~mm}$.

The transmission curve, $c$, figure 4 , of this mineral shows small absorption bands at $3.75,5.75,6.15$, and $6.55 \mu$; a very large band, at $4.55 \mu$, is characteristic of sulphates. This mineral was investigated previously, and is included here to illustrate the great difference in the opacity of the hydrous and the anhydrous mineral. (See curves $a$ and $c$, in which the samples have practically the same thickness.) 
Selenite, $\mathrm{CaSO}_{4}+2 \mathrm{H}_{2} \mathrm{O}$. -The sections examined were cleavage pieces split parallel to the $b$ axis; the thicknesses being $a=0.648$ $\mathrm{mm}, b=0.093 \mathrm{~mm}$, respectively. Since $2 \mathrm{I}$ per cent of selenite is

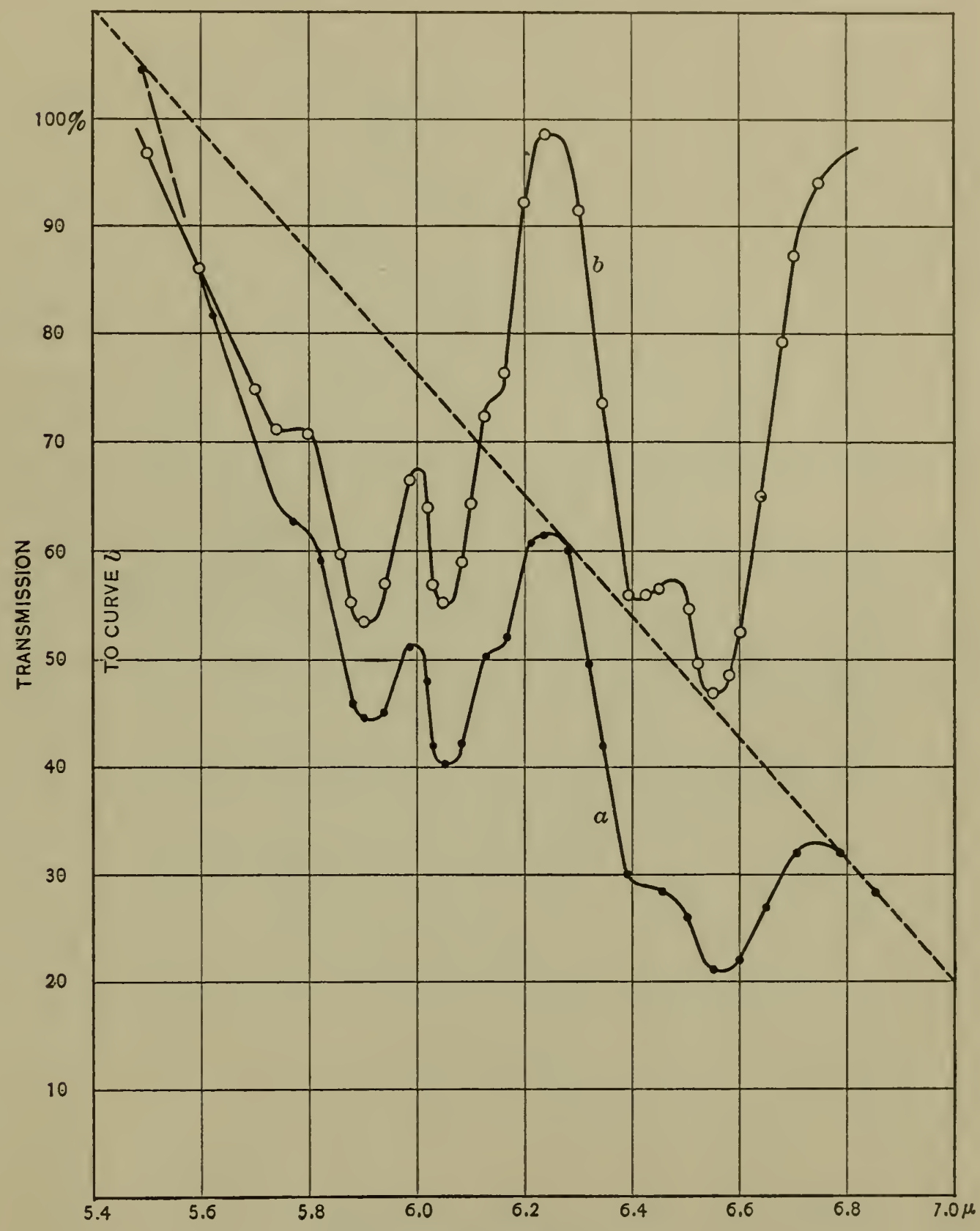

Fig. 3.-A tmospheric Water Vapor

water, the thickness of the water if free would be 48.8 per cent (sp. gr. of selenite is $2.33 ; 2.33 \times 2 \mathrm{I}=48.8$ ) of the thickness of the specimen, or $a=0.3 \mathrm{I} 7 \mathrm{~mm}$ and $b=0.046 \mathrm{~mm}$ of water. 


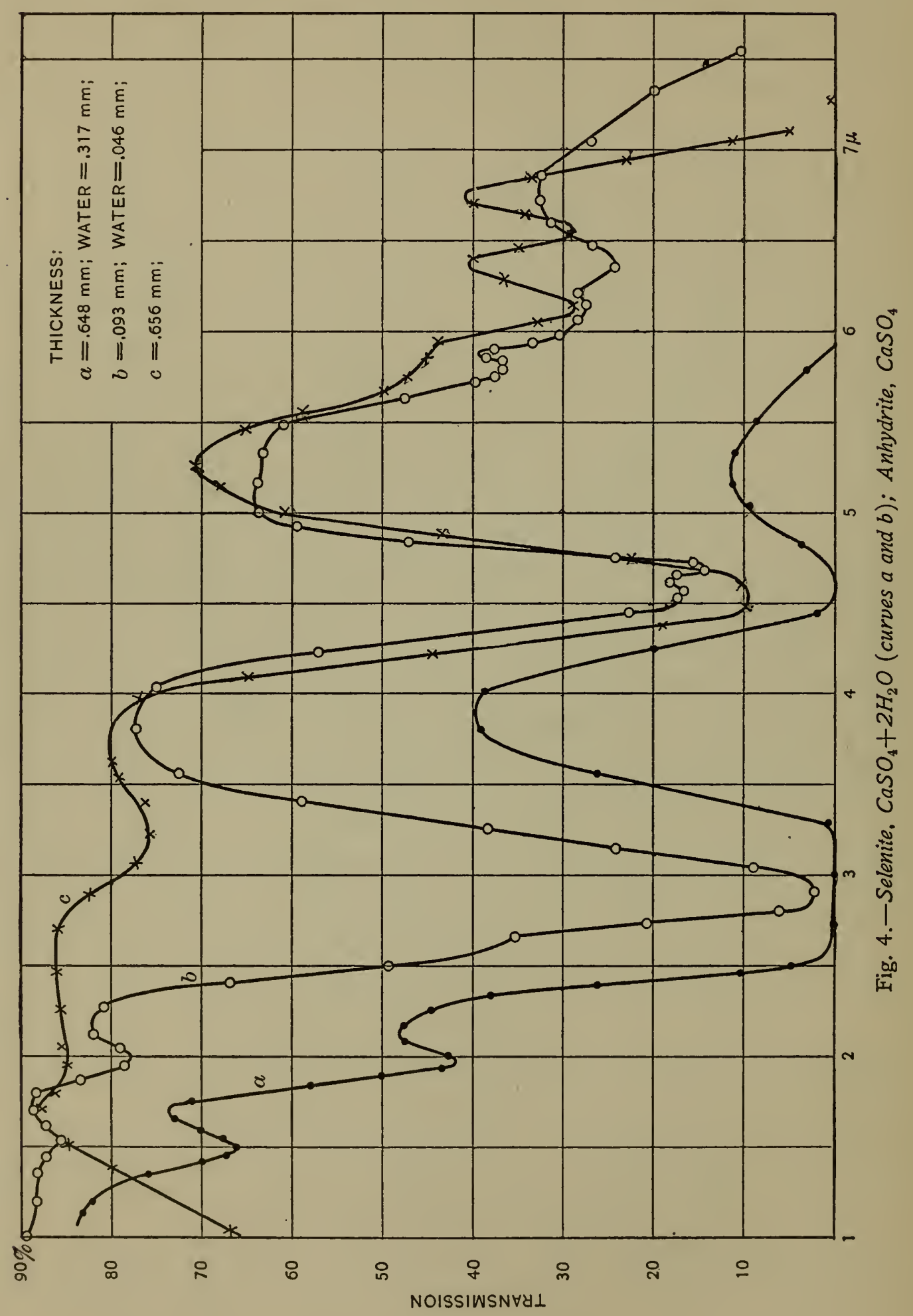


Of all the minerals investigated, containing water of crystallization, this and the following one are the most conspicuous for demonstrating the effect of water upon the absorption spectrum of substances. The absorption bands of water at 1.5, 2.0, 3 , $4.75,6.0$, and $6.5 \mu$ are very conspicuous in spite of the anhydrite bands which confuse matters at $6 \mu$. It is to be noticed that a layer of water in its free liquid state, curve $d$, figure $\mathrm{I}$, is far more opaque than an equivalent layer, curve $a$, figure 4 , when held in a crystal. This is evident from the fact that the $0.31 \mathrm{~mm}$ layer of water is entirely opaque beyond $2.5 \mu$. In fact, the transmission spectrum of selenite indicates the presence of water in more nearly the vapor state, in which it is possible to resolve the large bands into smaller ones-see figure 3 . This change in density of water in the process of crystallization involves energy changes which may require consideration in connection with the question of thermal equilibrium in dehydration.

In previous investigations ${ }^{16}$ partially and completely dehydrated, also rehydrated samples of selenite were examined, to which reference must be made in order to fully appreciate the bearing of this data upon the question of water of crystallization.

$\mathrm{Opal}, \mathrm{SiO}_{2}+x \mathrm{H}_{2} \mathrm{O}$.- Samples of opal and quartz have been examined previously. ${ }^{16}$ Quartz has small absorption bands at $2.9,4.35,5.02,5.3,6.0,6.26$, and $6.65 \mu$. The band at $2.9 \mu$ is barely observable in a section $0.1 \mathrm{~mm}$ in thickness. Curve $c$, figure 5 , gives the transmission of a section $1.435 \mathrm{~mm}$ in thickness, cut perpendicular to the optic axis. The maximum lies at $2.88 \mu$. This absorption band is so weak that it can not interfere with the water band at $3 \mu$. The bands at 6 and at $6.26 \mu$ form a composite with the water band at $6 \mu$, of which the maximum appears at 6. $1 \mu$. The group of atoms in quartz is very strong and maintains its characteristics, more or less sharply defined, in the various silicates investigated.

Opal, amorphous quartz, contains variable proportions ( 2 to 30 per cent) of water. It shows no traces of crystallization. It is considered a solid solution, for the water contained is a function of the vapor pressure. 
The transmission curve of opal has the general outline ${ }^{16}$ of the curve for water and contains the bands of water at I.5, 2, $3,4.75$, and $6 \mu$. The latter is complex, as mentioned above.

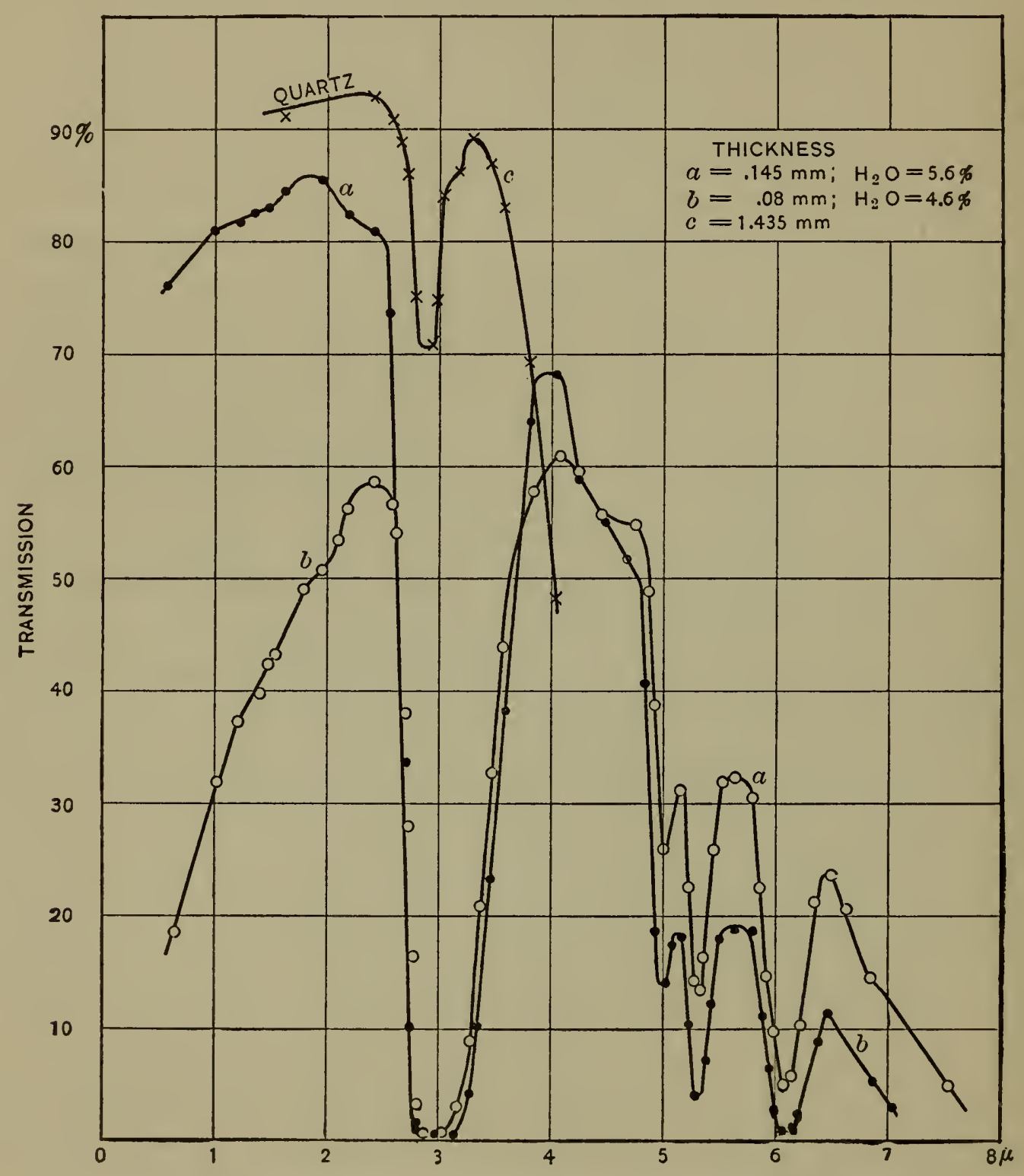

Fig. 5.-Opal, $\mathrm{SiO}_{2}+x \mathrm{H}_{2} \mathrm{O}$; Quartz, $\mathrm{SiO}_{2}$

For the present work the samples of opal were not perfectly transparent, which caused a scattering of the rays shorter than $2.5 \mu$. In figure 5 , curve $a$ gives the transmission of a sample of opal (from Queretaro, Mexico) o.r $45 \mathrm{~mm}$ in thickness, and containing 5.6 per cent of water. In transmitted light it showed a 
slightly milky white color which scatters the light to $2 \mu$. Curve $b$ gives the transmission of a whitish semitranslucent sample (from Silesia) $0.08 \mathrm{~mm}$ in thickness and containing 4.6 per cent of water. The equivalent layer of water for curve $a$ is $t=0.018$ $\mathrm{mm}$, and for curve $b$ it is $\mathrm{t}=0.0077 \mathrm{~mm}$. The rapid decrease in the general transmission beyond $4 \mu$ is due to the great opacity of quartz beyond $3 \mu$.

In figure 6 is given, curve $a$, the transmission of a semitranslucent sample of opal, $\mathrm{t}=0.105 \mathrm{~mm}$ in thickness, originally containing 3.6 per cent of water. The equivalent layer of water (sp. gr. of opal =2.I) is $0.0079 \mathrm{~mm}$. It was found possible to dehydrate the specimen without seriously increasing the inhomogeneity, as illustrated at 2 to $3 \mu$. In order to dehydrate the specimen, it was necessary to dismount the section from its cardboard support and place it in a porcelain tube which was then heated with a bunsen flame or blast lamp. The specimen was weighed before and after heating, and knowing the water content before heating it was possible to compute from the loss in weight the water remaining after heating. For example: Starting with the section weighing $32.037 \mathrm{mg}$ the loss in weight was $0.360 \mathrm{mg}$. The original water content was 3.6 per cent, from which it was computed that for curve $b$, figure 6 , the water content was 2.5 per cent. The weighings were made by Mr. W. C. Bishop, whose long experience in such work insured both speed and high accuracy. The weighings were made on an assay balance taking a maximum load of I gram. The working sensitivity was I $\mathrm{mg}=\mathrm{IO}$ divisions; probable error of a single weighing 0.002 to $0.005 \mathrm{mg}$. It was found that the weighings became constant in less than Io minutes after dehydration. It will be shown presently that this specimen absorbed about 0.06 per cent of water per day. Since the weighings were completed and the specimen was remounted within I5 minutes after dehydration, and since the observations on the absorption band at $3 \mu$ were completed within 45 minutes after heating the specimen, this question of reabsorption (so frequently asked by all comers) needs no further consideration. Curves $c, d$, and $e$ were obtained in the same manner as curve $b$. Each time the section was dismounted there was a slight loss due to breakage, so that after obtaining curve $e$ the specimen was placed 


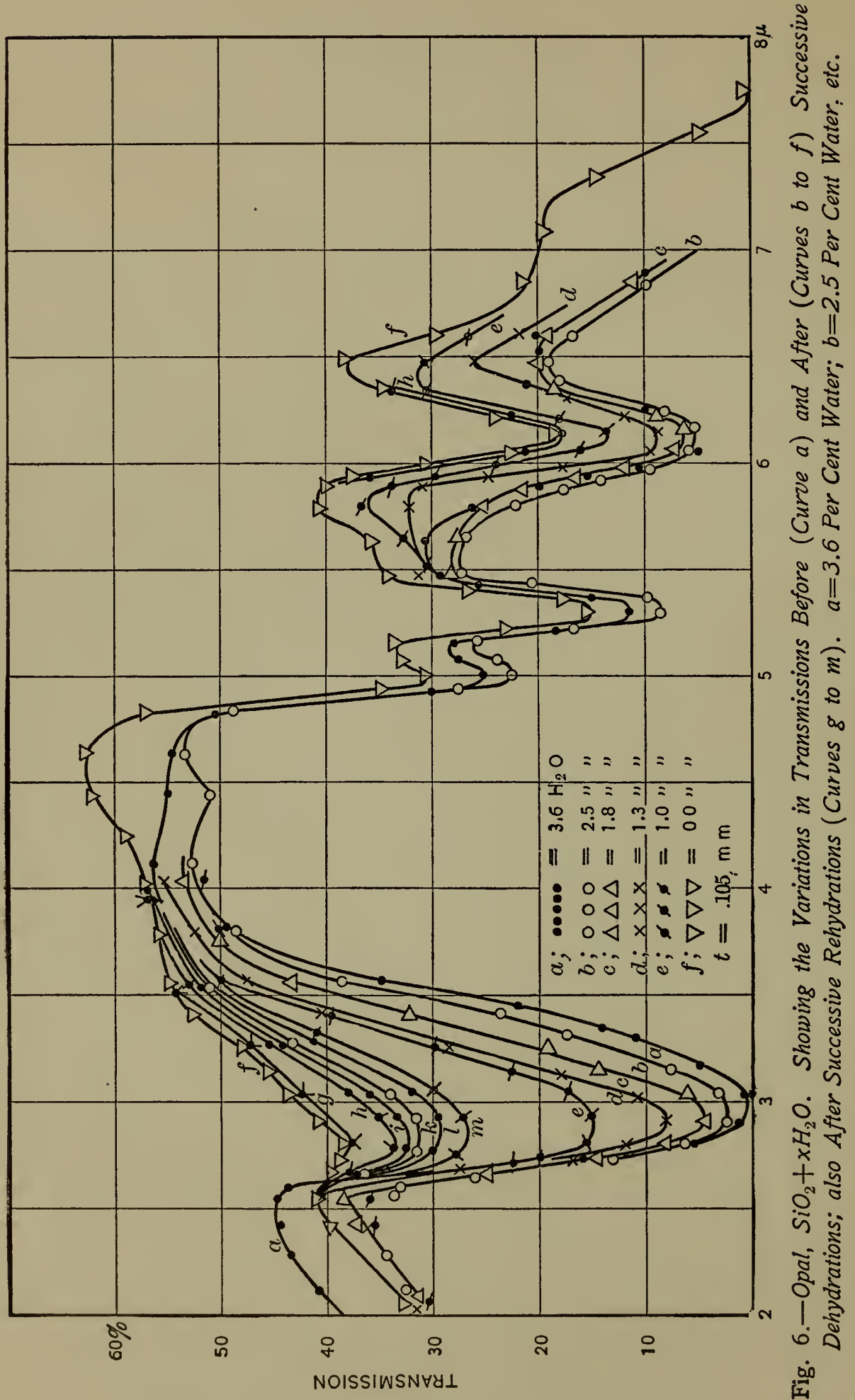




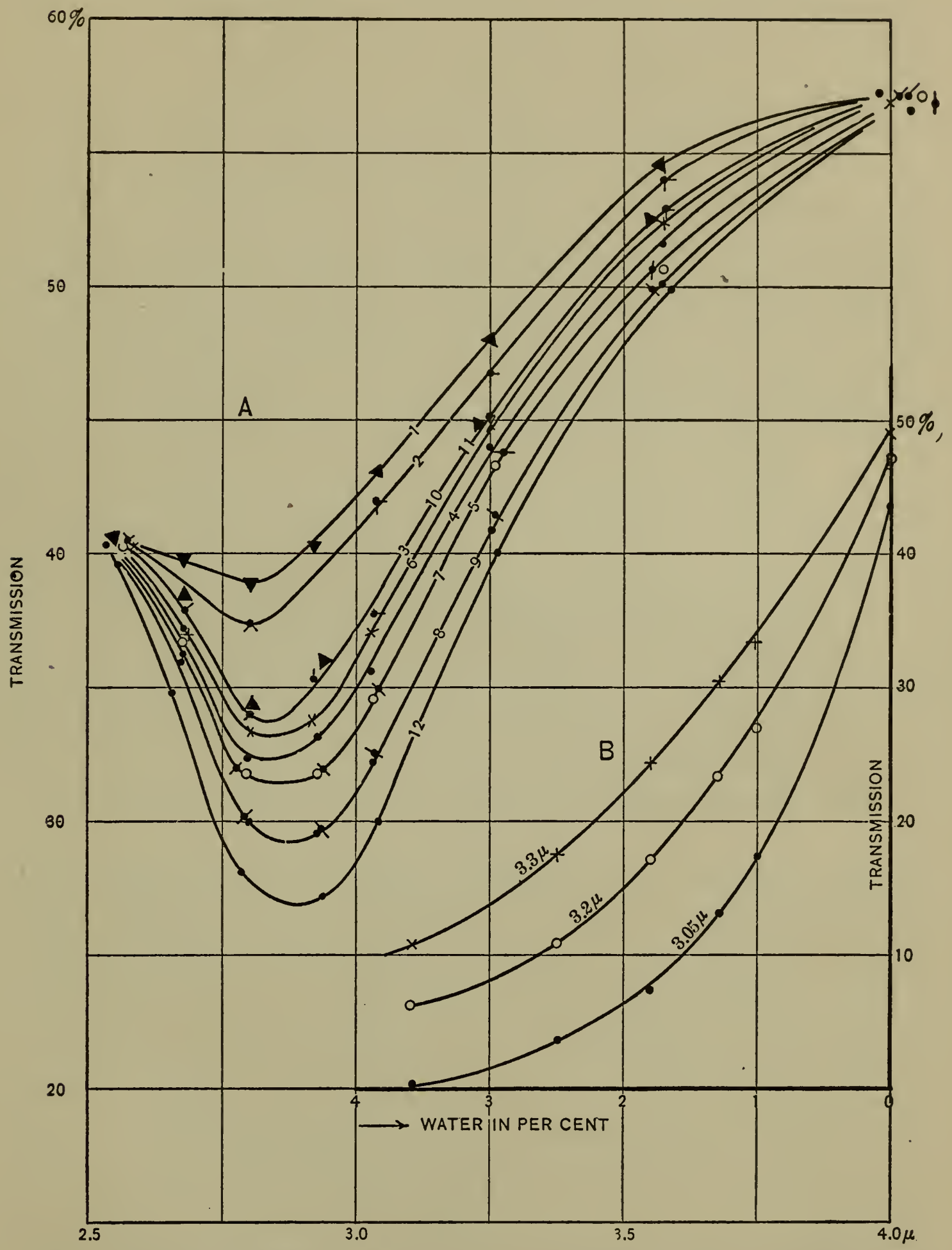

Fig. 7.-Showing the Variation in the Water Content of Opals on Successive Days After Dehydration 
in a platinum receptacle and heated to a bright red $\left(700^{\circ}\right)$ for one hour. It was then mounted permanently upon the cardboard support and on examination gave curve $f$, figure 6 . The small band at $2.9 \mu$ remains; but whether it is due entirely to $\mathrm{SiO}_{2}$ or whether it still represents a trace of water remains undetermined. After standing overnight it reabsorbed moisture, giving curve $g$. Two days thereafter the transmission had fallen to curve $h$. This examination of the reabsorption of water was continued for $\mathrm{I} 7$ days after dehydration, the relative humidity of the laboratory being determined daily by means of an aspiration hygrometer. The daily variation of the absorption band at $3 \mu$ is shown in figure $7-\mathrm{A}$, which represents curves $f, g, \ldots m$, figure 6 , on a different scale. The numbers attached to the various curves

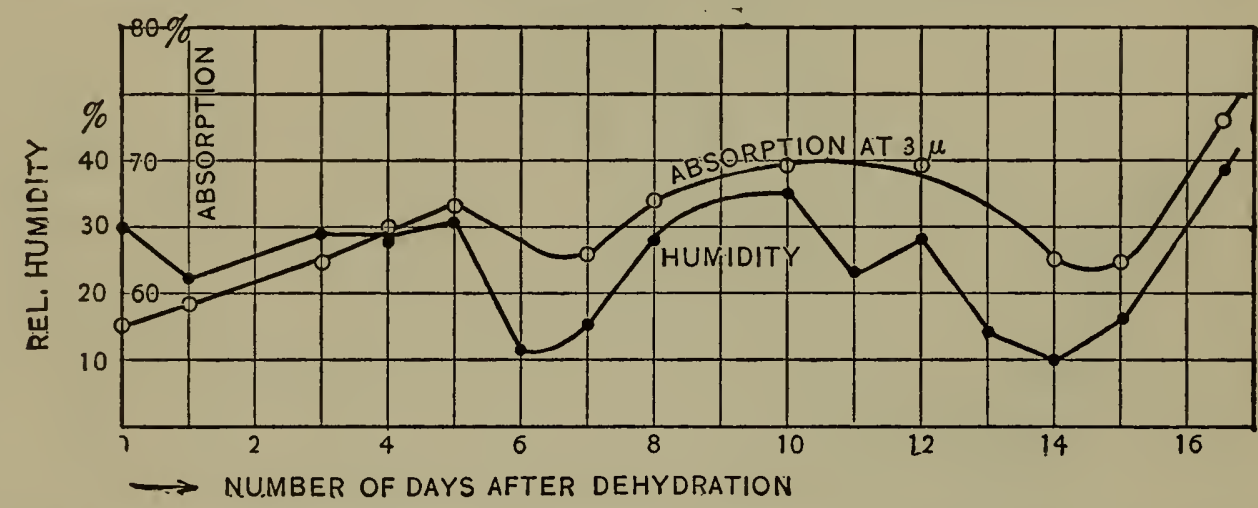

Fig. 8.-Showing the Variation of the Water in Opal with Variation in the Atmospheric Humidity

indicate the order in which they were observed. In figure $7-\mathrm{B}$ are given several isochromatic transmission curves, obtained from curves $a, b, c, d$, and $e$ of figure 6 . From these curves it is possible to obtain a rough estimate of the water content represented in the curves 2 to 12 , figure $7-\mathrm{A}$. The disappearance of the water band at $6.1 \mu$ is not so marked as at $3 \mu$, but it is evident that in making allowance for variation in homegeneity this part of the curves can not be superposed. The bands at $5.0 \mu$ and $5.3 \mu$ are due entirely to silica and there would be no difficulty in superposing them. It will of course be understood that in the frequent remounting of this specimen it was not possible to obtain the transmission of exactly the same part of the section each time.

During the examination of the rehydration of this sample of opal there were two cold periods when the relative humidity 
decreased to ro per cent. It was then found that the opal became dehydrated. This is illustrated in figure 8 , which shows the variation of water in opal (as measured by the variation in the absorption) with variation of atmospheric humidity. There is a lag of about half a day in the hydration curve.

\section{GROUP 2. MINERALS CONTAINING WATER OF CONSTITUTION}

Under this heading are collected the minerals which contain water, but which do not show the characteristic absorption bands found in water in its free liquid state.

Muscovite $\mathrm{Mica}, \mathrm{H}_{2} \mathrm{KAl}_{3}\left(\mathrm{SiO}_{4}\right)_{3}$. - The transmission spectra are given in figure 9. Curve $a$ was obtained with a rock salt prism, while curves $b$ and $c$ were observed with a fluorite prism. The thickness was $0.04 \mathrm{~mm}$. Curve $b$ shows the transmission of the specimen after dehydration. The absorption bands are common to silicates; and none are in common with those of water. The band of selective reflection beyond $9 \mu$ does not seem to be affected by the constitutional water, as should be the case, since it is known that these bands are due to the $\mathrm{SiO}_{2}$ radical. The other bands disappear on dehydration. The layer of mica is too thin, and the inhomogeneity is too great to show the weak absorption band of silica at $2.9 \mu$. A more complete list of minerals containing water of constitution is given in previous communications ${ }^{17}$ on this subject.

Tremolite, $\mathrm{CaMg}\left(\mathrm{SiO}_{3}\right)_{4}$. -The transmission of a section of this mineral, $0.23 \mathrm{~mm}$ in thickness, was described in a previous paper. ${ }^{18}$ The section was kindly prepared by Dr. Allen, of the Geophysical Laboratory, who found 2 per cent of water, which appears to be present in solid solution. The section of tremolite was of sufficient thickness to insure detecting the water, provided its absorption is as great as in the liquid phase. The equivalent layer of water was $0.0138 \mathrm{~mm}$, but no water bands could be detected. It is evident from this and from the transmission of a layer of water 0.0I $4 \mathrm{~mm}$ in thickness (Fig. $\mathrm{I}, b$ ), that the water in tremolite is in an entirely different condition from that which obtains in the crystals and in the solid solutions previously inves-

17 This Bulletin, 2, p. 457; 1907. Carnegie Publication No. 65.

${ }_{18}$ Physical Review, 30, p. 326; 19 10. 
tigated by this method of analysis. Thinking that further information would be disclosed, the investigation of this interesting mineral was undertaken anew, using samples of the same specimen previously examined.

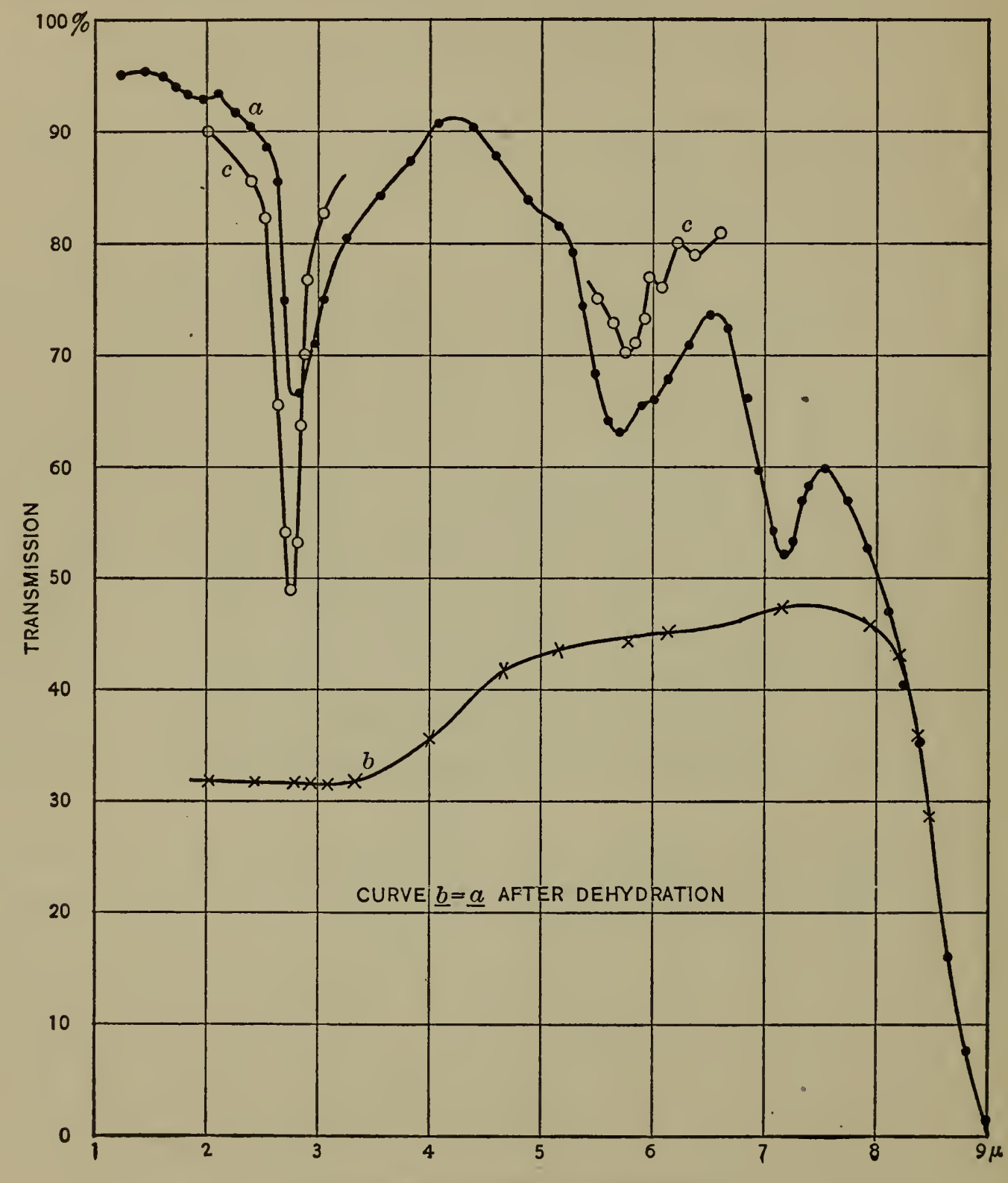

Fig. 9.-Muscovite Mica, $\mathrm{H}_{2} \mathrm{KAl}_{3}\left(\mathrm{SiO}_{4}\right)_{3}$

In the earlier work ${ }^{19}$ it was found that a sample of amphibole (probably hornblende) showed no traces of water, the small absorption band at $2.9 \mu$ being similar to that found in feldspars.

${ }_{19}$ Carnegie Publication No. 65, p. 64 . 


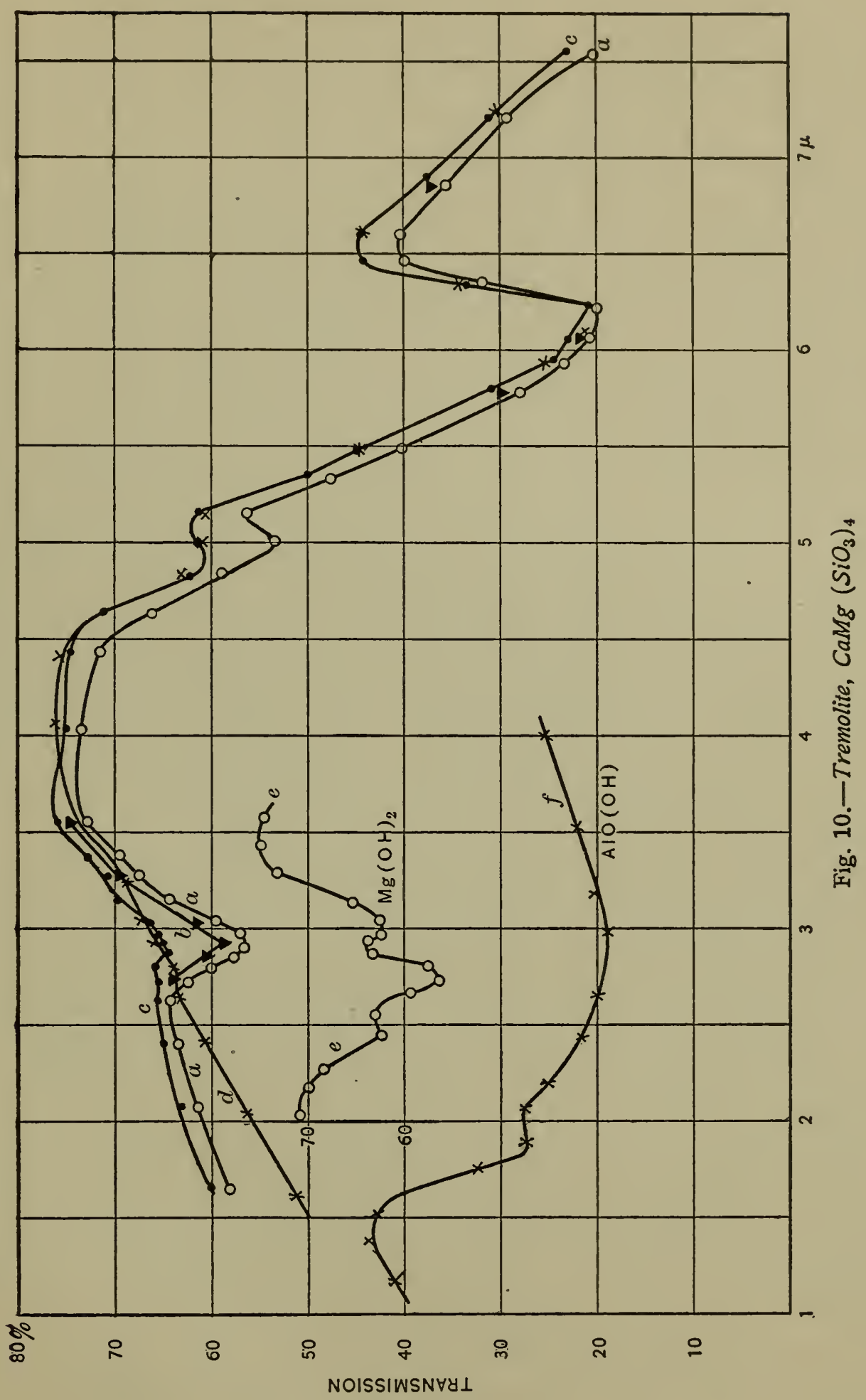


The sample of tremolite used in the present examination was $0.095 \mathrm{~mm}$ in thickness. The small absorption bands at 2.9 and $6.2 \mu$ are, therefore, not so sharp as found in the $0.23 \mathrm{~mm}$ sample previously examined. On the assumption that 2 per cent of water was present, the equivalent layer of water (sp. gr. of tremolite is 3 ) is $0.0057 \mathrm{~mm}$ in thickness.

The transmission of this sample before dehydration is given in curve $a$, figure Io. Curve $b$ represents the transmission after heating the specimen for half an hour at $200^{\circ}$ in an atmosphere of dry hydrogen. The curve is superposable upon curve $a$. Curve $c$ gives the transmission after heating the specimen in an electrically heated porcelain tube furnace at $500^{\circ}$ for five hours. In this case the absorption band at $2.9 \mu$ is practically destroyed. Curve $d$ gives the transmission after heating the specimen in the electric furnace at $925^{\circ}$ for five hours. The absorption is identical with that of curve $c$, showing that most of the chemical change was brought about at $500^{\circ}$. In the dehydration the specimen became slightly inhomogeneous, which caused a scattering of the radiation to $3 \mu$. The band at $2.9 \mu$ has entirely disappeared, showing that it belonged to the compound that existed before dehydration. The bands at 5 and $6 \mu$ have undergone no change. They belong to anhydrous silicates; and the general outline of the transmission curve is not unlike that of the feldspars. ${ }^{19}$

In figure io are also given the transmission curves of brucite, $\mathrm{Mg}(\mathrm{OH})_{2}$, and of diaspore, $\mathrm{AlO}(\mathrm{OH})$. The brucite curve shows a complex region of absorption bands at $2.5,2.75$, and $3.0 \mu$. The $3 \mu$ band is found in substances having $\mathrm{OH}$ groups. In diaspore the absorption is very complex and the individual bands, which no doubt exist, are not resolved. Bauxite, $\mathrm{Al}_{2} \mathrm{O}(\mathrm{OH})_{4}$ and göthite, $\mathrm{FeO}(\mathrm{OH})$, also have wide bands at $3 \mu$.

The chemical composition of amphiboles, of which tremolite is a species, does not appear to be definitely known, some ${ }^{20}$ arriving at the conclusion that the water is present as "dissolved water," while others ${ }^{21}$ considered the water to be present as hydroxyl

${ }^{19}$ Carnegie Publication No. 65 , p. 64.

${ }^{20}$ Allen and Clement: Amer. Jour. Sci., 26, p. ror; 1908.

${ }^{21}$ Penfield and Stanley: Amer: Jour. Sci., 23, p. 23; 1907. 
groups combined with $\mathrm{Al}_{2} \mathrm{O}_{3}$ and $\mathrm{Fe}_{2} \mathrm{O}_{3}$. From the present data it is evident that the water in tremolite is not present in the same condition as in other substances containing water in solid solution or dissolved water. Attention has already been called to the fact that in selenite the density of water is much less than in the free state, so that a layer of water equivalent to $0.31 \mathrm{~mm}$ transmits radiation to $6 \mu$, while a film of water $0.31 \mathrm{~mm}$ in thickness is completely opaque beyond $2.5 \mu$. The "density" of water in opal is far less than in selenite, but its opacity is of the same order of magnitude. Again, if we consider opal, having 3 per cent of water $(\mathrm{sp} . \mathrm{gr} .=2)$, we find that 6 per cent of the thickness of the section is water and the absorption bands of water are very prominent, while in tremolite (sp. gr. 3 ), in which the thickness of the water layer is also 6 per cent, the absorption bands of water are entirely lacking.

From the present data it appears that in tremolite the water is constitutional, with $\mathrm{OH}$ groups, the small band at $2.95 \mu$ being complex, as in the other hydroxides just cited. This is, of course, contrary to the vapor pressure experiments; but it is the most satisfactory conclusion to be drawn from the present experiments.

\section{GROUP 3.-MISCELLANEOUS SUBSTANCES}

Under this heading are described the absorption or reflection spectra of several substances having no direct bearing on the present problem. They are, of course, only supplementary to previous work to which reference must be made in order to gain an intelligent understanding of their spectral characteristics.

Gelatin.-This substance belongs to the albumens, of which the chemical constitution is unknown. They contain $\mathrm{C}, \mathrm{H}, \mathrm{O}, \mathrm{N}$, and $\mathrm{S}$. The present examination was made to determine the variation in intensity of the water bands with variation in the water content. The sample examined was a sheet of commercial material $0.025 \mathrm{~mm}$ in thickness, and it was perfectly clear. Curve $a$, figure II, gives the transmission curve before dehydration, and curve $b$ gives the transmission after partial dehydration, the film being tinged a faint light brown. The peculiarity of these curves is the absence of absorption bands at I.5 and $2 \mu$. The general 
appearance of the transmission curve is entirely unlike that of water, and of substances containing water. The absorption bands are sharp and narrow, as usually found in carbohydrates. In fact, the whole curve appears as though the water were present as "water of constitution," the sharp band at $3 \mu$ being due to $\mathrm{OH}$ groups. The 3.4 and 6.8 and $7.3 \mu$ bands are characteristic of substances rich in $\mathrm{CH}_{2}$ and $\mathrm{CH}_{3}$ groups. The very sharply

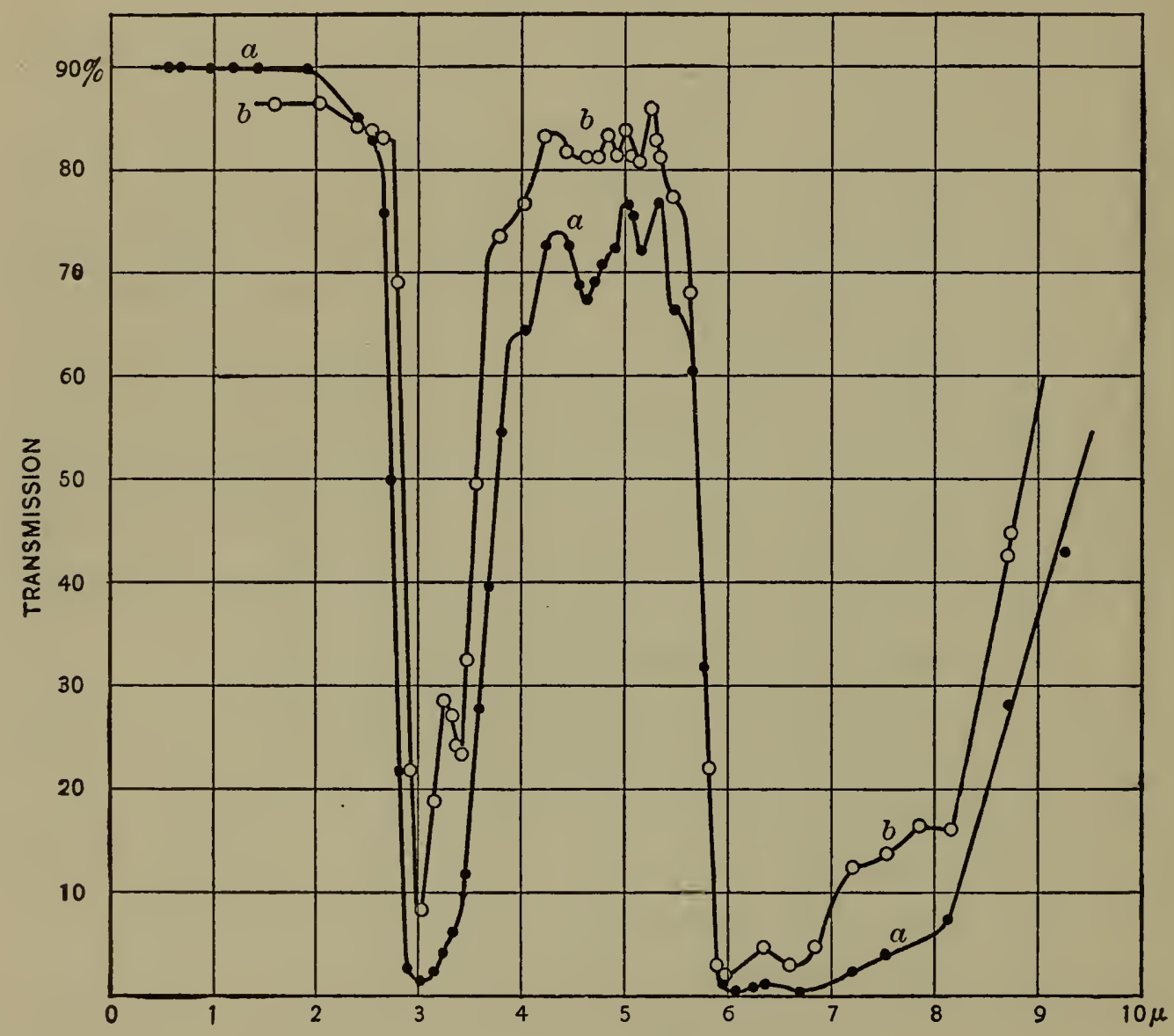

Fig. 11.-Gelatin (Curve b After Dehydration)

bounded region of great opacity at 6 to $8 \mu$ is characteristic of carbohydrates containing $\mathrm{NO}_{2}$ groups. There are absorption bands at $2.4,3.0,3.43,4.0,4.6,4.9,5.15,5.5,6.0,6.8,7.3$, and 8.I $\mu$.

Oleic acid, $\mathrm{C}_{17} \mathrm{H}_{33} \mathrm{COOH}$. - This substance was examined to obtain a check on previous work done with a rock-salt prism and to arrive at an explanation of the peculiar absorption bands found in olive oil and in linseed oil. In all cases the film of oil or 
acid was contained between clear fluorite plates, separated by a ring of tinfoil $0.007 \mathrm{~mm}$ in thickness, curve $c$, figure $\mathrm{I} 2$.

The paraffin oils have a series of harmonic bands at $1.71,3.43$, 6.86, (7.35), and $\mathrm{r}_{4} \mu$. In the fatty acids the region of $3.5 \mu$ and $7 \mu$ is complex and a large absorption band is found at 5.8 to $5.9 \mu$.

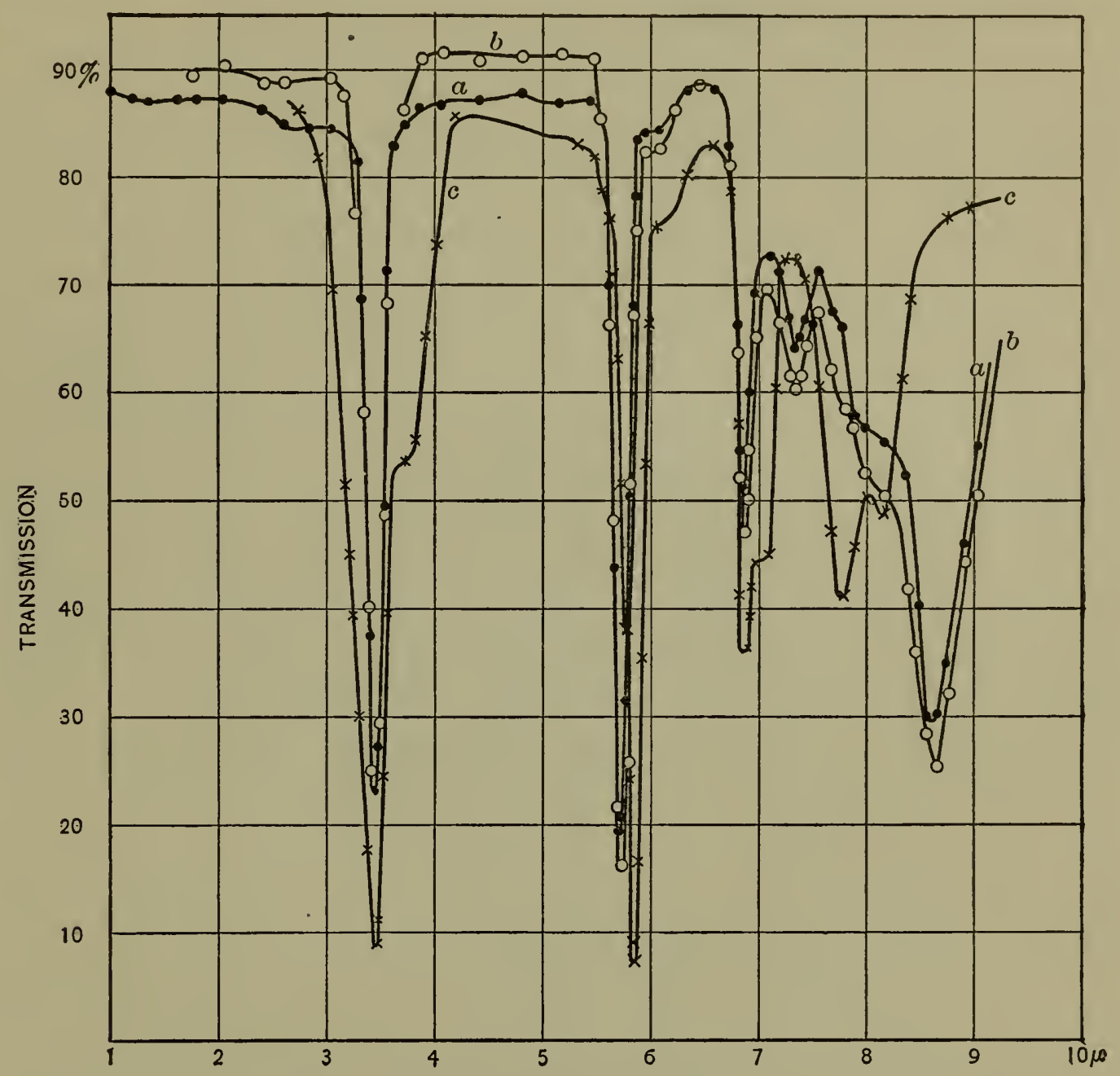

Fig. 12.-Olive Oil (a); Linseed Oil (b); Oleic Acid (c). Thickness $=.007 \mathrm{~mm}$

The latter band was sometimes found in some of the heavier paraffin oils when the absorption cell was exposed to oxidation. ${ }^{22}$

In previous investigations the intense band at $5.8 \mu$ was found in all substances containing the $\mathrm{C}=\mathrm{O}$ group, as in $\mathrm{COOH}$. It was also found that in passing from a saturated fatty acid (stearic

${ }^{22}$ See Figs. 64,72 , and 73 , Publication No. 35 , Carnegie Institution of Washington, I905. 
acid, $\mathrm{C}_{17} \mathrm{H}_{35} \mathrm{COOH}$ ) to an unsaturated fatty acid (oleic acid, $\mathrm{C}_{17} \mathrm{H}_{33} \mathrm{COOH}$ ) there is no marked change in the absorption spectrum. The most noticeable feature, as the number of $\mathrm{CH}_{2}$ and $\mathrm{CH}_{3}$ groups increases, is the disappearance of small bands at 3.8 and $7.08 \mu$, and an increase in sharpness of the $3.43,6.86,7.35$, and $8.65 \mu$ bands which are characteristic of the paraffin oils. In other words, as the ratio of the total number of $\mathrm{CH}_{2}$ and $\mathrm{CH}_{3}$ groups to the $\mathrm{COOH}$ groups increases (c. f. acetic acid, $\mathrm{CH}_{3} \mathrm{COOH}$, and stearic acid, $\mathrm{C}_{17} \mathrm{H}_{35} \mathrm{COOH}$ ) the characteristic absorption bands of the $\mathrm{CH}_{2}$ and $\mathrm{CH}_{3}$ groups become more prominent with the disappearance of the bands characteristic of the $\mathrm{COOH}$ groups. The work is also instructive in showing that not until we can use a very much larger dispersion than is now employed can we expect to obtain much information from the study of complex absorption bands, such as are found in the fatty acids. As indicated elsewhere, ${ }^{19}$ a detailed study of individual groups of compounds is highly desirable, now that a preliminary survey of the various groups of compounds has been made. It seems quite probable that by using a very much larger dispersion than has been employed heretofore, some of the older data will not be verified, but will be found to be mere hints to much more useful information. It is to be noticed that the fluorite prism resolves the band at 3.43 and $3.8 \mu$, which was not possible in the previous investigation with the rock-salt prisin. The maxima of the absorption bands of oleic acid occur at $3.43,3.8,5.86,6.1,6.86,7.08,7.75$, and 8.1 $5 \mu$. The sample examined was a highly purified one from Merck.

Olive oil.-The transmission curve of this substance is shown in curve $a$, figure $\mathrm{I} 2$; (thickness of film $=0.007 \mathrm{~mm}$ ). The curve is conspicuous for the sharpness of the absorption bands at 3.43 and $5.7 \mu$. This oil is a mixture of various fatty acids. The 3.8 and $7.08 \mu$ bands are absent. There are absorption bands at $2.7,3.43$, $5.7,6 . \mathrm{I}, 6.86,7.35,7.75,8.15$, and $8.65 \mu$. The $5.7 \mu$ (shifts to 5.9 in some compounds) is characteristic of substances containing $\mathrm{CO}$ groups.

Linseed oil.-This oil consists entirely of unsaturated acids, including oleic acid (one double bond) and linolenic acid, $\mathrm{C}_{17} \mathrm{H}_{2, \mathrm{j}} \mathrm{COOH}$ (three double bonds). The absorption band at $5.7 \mu$, curve $b$, figure 12 , is shifted from that of the preceding (more 
saturated) oil, being at $5.75 \mu$, while in the pure unsaturated acid, oleic acid, the band occurs at $5.85 \mu$. No explanation is at hand for the occurrence of the band at $8.65 \mu$, which is found in the paraffin oils but does not occur in any of the fatty acids. The sample examined was a standard test sample, free from adulterants. The maxima of the prominent absorption bands occur at $3.43,5.75,6.1,6.86,7.35,7.75,8.15$, and $8.65 \mu$.

Chitin.-This is a complex nitrogenous substance the chemical structure of which is unknown. The samples examined were the outer, horny, amorphous integument covering various species of

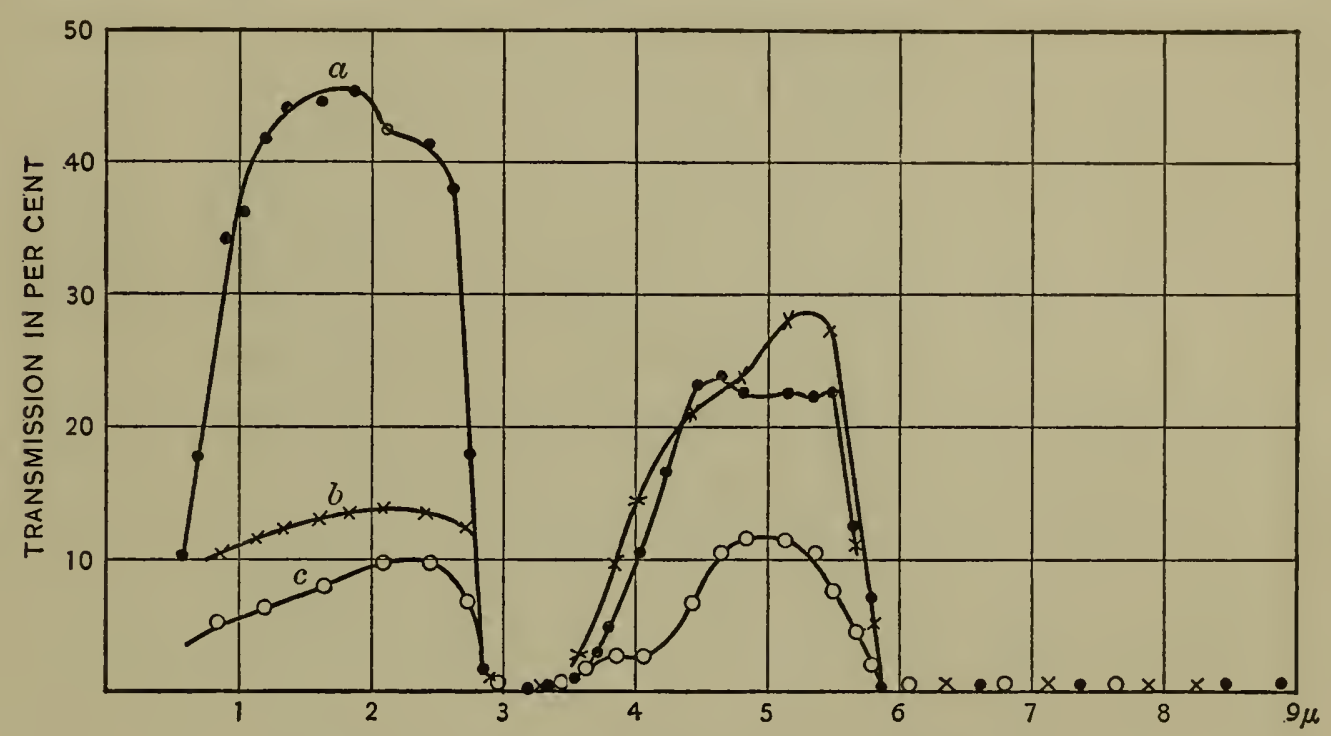

Fig. 13.-Chitin (the Chitinous Layer of Fireflies)

fireflies, the color varying from white (covering of the luminous organs) to a deep brown. The examination was made in connection with the question ${ }^{23}$ whether or not an appreciable amount of energy, of wave lengths greater than 2 to $2.5 \mu$ could be transmitted (radiated) through the body of the insect, assuming that such energy is generated in the photogenic cells. In figure $\mathrm{I} 3$, curve $a$ gives the transmission through one of the horny abdominal segments of a dried specimen of the "Cuban firefly," Pyrophorus noctilucus. This integument is dark brown (in reflected light) which causes a heavy absorption through the visible spectrum to the red, at which point the transmission rapidly increases. In

${ }^{23}$ Ives and Coblentz: This Bulletin, 6, p. 32I; I909. Coblentz: Electrical World, 56, p. IOI2; I IIO. 
this firefly, it may be recalled, the abdominal light is emitted through a slit between two of the segments of which the above is a sample. The size of the specimen examined was about I.5 by $7 \mathrm{~mm}$. In this same illustration, figure $\mathrm{I}_{3}$, curve $b$ gives the transmission through one of the eyelike fenestrate membranes on the thorax of the "Cuban firefly," and through which is emitted the so-called "thoracic light." The specimen was only 1.5 by $2 \mathrm{~mm}$ and hence very difficult to examine. After removing all the photogenic cell ligaments which adhered to it this specimen was fairly translucent. In the region from $I$ to $2 \mu$ the transmissivity is probably higher than observed, the low values being due to scattering of the radiation in passing through the specimen.

Curve $c$, figure 13 , gives the transmission through the outer integument covering the photogenic cells of Photinus pyralis. The specimen examined was a single dried abdominal segment, I. 5 by $4 \mathrm{~mm}$, which had been moistened in water and freed from all ligaments and photogenic material. The specimen was not very smooth and it was only semitranslucent. No doubt a better sample could have been prepared by dissecting a fresh undried insect. In both curves $b$ and $c$ the opacity at $\mathrm{I} \mu$ to $2 \mu$ and at $5 \mu$ is greatly increased by scattering of the transmitted radiation which did not reach the bolometer. However, as was anticipated in a previous communication, these curves have the characteristic absorption spectrum of complex carbohydrates, in which there is great (and usually complete) opacity from $2.8 \mu$ to $3.8 \mu$, and beyond $6 \mu$, with a fairly transparent region at $4.5 \mu$ to $5 \mu$.

It may be noticed that these specimens were dry. If they had been fresh then the water would have absorbed most of the radiation at 4 to $5 \mu$.

The data show that but little radiant energy (if generated in the photogenic cells) of wave-lengths greater than $2.5 \mu$ will get out of the insect's body. That which does get out, at 4 to $5 \mu$, will be so weak in intensity that it will hardly be distinguishable from the emission spectrum of the "animal heat" which has its maximum emission in the region of $7 \mu$.

Sylvite, $\mathrm{KCl}$.-The fact that sylvite has absorption bands in the region of $3 \mu$ and $7 \mu$ was mentioned by Rubens ${ }^{24}$ but no further

${ }^{24}$ Rubens: Ann. der Phys., 53, p. 267; 1894. 
reference being made thereto by other writers the question arose ${ }^{25}$ whether this is a common property of this mineral or whether the bands described by Rubens were due to impurities. The present

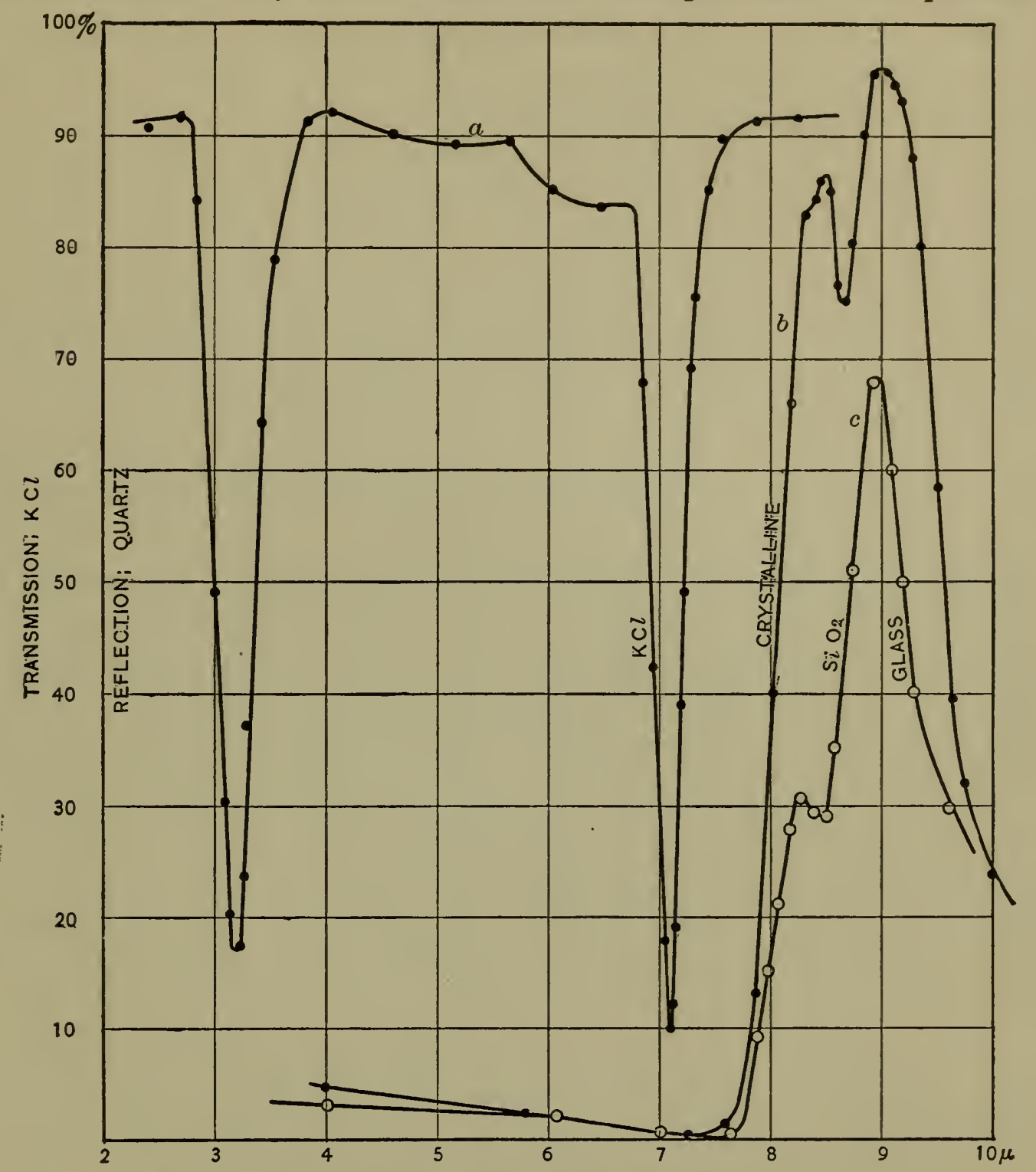

Fig. 14.-Sylvite, $\mathrm{KCl}$. Quartz, $\mathrm{SiO}_{2}$; Crystalline $b$ and Amorphous $\mathrm{C}$

examination was undertaken as a result of inquiries sent to this bureau as to the suitability of sylvite for radiometer ${ }^{26}$ windows, and as to its freedom from absorption bands.

25 Kayser: Spectroscopie, vol. 3, p. 387 .

${ }^{26}$ It seems desirable to employ the term "radiometer" instead of the more clumsy expression "radiationmeter" when the general instrument is mentioned, using the term "bolometer," "thermopile," "radiomicrometer," "radiobalance," "Nichols radiometer," etc., when the reference is to the specific instrument. 
The transmission of sylvite curve $a$, figure $\mathrm{I}_{4}$ (thickness $=4 \mathrm{~mm}$ ) shows two very sharp absorption bands, at $3.18 \mu$ and $7.08 \mu$, respectively, and a smaller depression at $6.2 \mu$. An interesting point in connection with these absorption bands is their assymmetry, indicating that they are double, just as was found true of the bands of residual rays ${ }^{27}$ at 62 to $70.3 \mu$.

The thickness of the plate of sylvite was $4 \mathrm{~mm}$. A very much thicker plate should be used to investigate the assymmetry at $3.6 \mu$ and $7 \cdot 3 \mu$.

Quartz, $\mathrm{SiO}_{2}$. - The reflecting power of a plate of crystalline quartz is given in curve $b$, figure $\mathbf{I} 4$. It was observed several years ago with a rock-salt prism, but never published because of the doubt as to the accuracy of the indications of the appearance of a double band at $8.3 \mu$ and $8.5 \mu$, and the assymmetry at $9 \mu$ and $9.2 \mu$. Recent investigations ${ }^{28}$ using a very much larger dispersion shows that these bands are complex.

Quartz glass.-The present sample of quartz glass was examined several years ago and describer in Carnegie Publication No. 97, page 22. The examination was made entirely separate from all the rest of that work, using a special adjustment of apparatus, which may account for the inconsistent results obtained, which showed an entirely different spectrum from that of crystalline quartz. There being no good reason why crystalline and amorphous quartz should give entirely different spectra at $7.8 \mu$ the work was repeated on the same sample previously exanined, using a vacuum bolometer which was far steadier than the old-style instrument previously employed.

In the present examination the rear surface of the quartzglass plate was painted black to avoid stray light. The results are shown in curve $c$, figure 14 . The first maximum at $8.3 \mu$

${ }^{27}$ Rubens and Hollnagel: Sitzber. Akad. Wiss. Berlin, p. 26: r910. Hollnagel. Inaug. Dissertation, Berlin, rgro.

${ }^{28}$ Trowbridge and Wood: Phil. Mag., 20, p. 898; Igro. Reinkober, Ann. der Phys., 34, p. 343; r9r r. 
reflects 3 I per cent, while the second maximum, at $8.95 \mu$, reflects 68 per cent. The band previously found at $7.8 \mu$ is entirely lacking, and the reflecting power throughout this whole region is too small to be measured, whereas in the previous examination the reflecting power was high, about 5 per cent. Up to the present time no explanation can be offered for the presence of the spurious band previously observed at $7.8 \mu$. The other reflection bands are practically the same as previously observed, and the whole spectrum appears much simpler than that of crystalline quartz. In the work recently described by Reinkober ${ }^{28}$ the positions and the intensities of the maxima of quartz glass are almost identical with the present results.

\section{LIGHT FILTERS WHICH ABSORB ALL THE INFRA-RED}

There are numerous problems in which it is desirable to separate the infra-red from the visible spectrum without employing a prism. The use of absorption screens is the most natural procedure, provided suitable material can be found. Water is the most opaque substance known, a layer I $\mathrm{cm}$ in thickness absorbing all wave lengths greater than $\mathrm{I} .4 \mu$. Substances which are perfectly transparent in the visible spectrum, and which have large absorption bands just beyond the visible, between 0.8 and $1.5 \mu$, are unknown. The nearest approach to the fulfillment of such a condition is the mineral bery ${ }^{29}$ which in polarized light (the ordinary ray) has a large absorption extending from $0.7 \mu$ to $\mathrm{r} \mu$ with a nuaximum at $0.86 \mu$.

Numerous searches have been made to find a substance which in solution with water absorbs all the radiation lying between $0.7 \mu$ and $\mathrm{r} .4 \mu$. The old idea that a solution of potassium alum absorbs more of the infra-red than pure water has been repeatedly

${ }^{29}$ Koenigsberger: Ann. der Phys., 61, p. 687; r897. 
proven erroneous. Of late, experimenters ${ }^{30}$ have been using solutions of ammonium-iron alum $\left[\left(\mathrm{NH}_{4}\right)_{2} \mathrm{Fe}_{2}\left(\mathrm{SO}_{4}\right)_{7}\right]$ claiming that it was more opaque than pure water. This is due to the fact that the solution is not entirely colorless. This is illustrated in figure $\mathrm{I}_{5}$, curve $a$, which gives the transmission of a saturated (at $25^{\circ}$ ) solution of this substance. The transparency gradually increases, so that at $\mathrm{I} .2 \mu$ the absorption is but little greater than same thickness of pure water. It is therefore evident that in experiments where an attempt is made to eliminate the infra-red from the visible radiation, e. g., in incandescent lamps, it is brought about with a great loss of light with but little gain in the attempt to eliminate the infra-red.

In measuring the luminous efficiencies of light sources Féry ${ }^{31}$ and others have separated the visible from the total radiation by means of solutions of copper salts, e. g., copper acetate of such concentration that the minimum of the absorption band was at $0.54 \mu$. The transmission curves of these salts coincide closely with the sensibility curve of the eye.

An efficient screen, either colored glasses or solutions of salts, permits the use of a surface bolometer, which is much better adapted than the linear bolometer for measuring radiation which is of low intensity. For example, the mercury arc consists of strong lines in the green and the blue and a series of strong emission bands in the region of 0.9 to $\mathrm{I} .3 \mu$. The water cell will not absorb this infra-red radiation, but, as will be shown presently, a weak solution of copper chloride will absorb it without serious loss of energy in the visible spectrum. Hence, the employment of a surface bolometer and an absorption cell of copper chloride, even if it does absorb some of the visible, will be far more efficient than the use of a linear bolometer. The latter requires a spectrometer, through the slit of which it is possible to pass only a small part of the light which can be used on a large surface bolometer.

It was therefore of interest to examine a series of solutions, which seemed promising as absorption screens, to determine the

${ }^{30}$ Lux: Zs. für Beleuchtungswesen, Heft., 16, p. 36 ; 1907. Russner: Phys. Zs., 8, p. 120; 1907 .

${ }^{31}$ Féry: Bull. Soc. Franc. de Physique, p. 148; 1908. Bull. Soc. Internat. des Électriciens, 9, p. 655; rgog. 
least concentration which would absorb all the infra-red radiation, and at the same time absorb but little in the green and the blue.

The transmission curves of a series of colored glasses were described elsewhere. ${ }^{32}$

For the present experiments a Nernst glower was used as a source of radiation. It was placed at a distance of about $10 \mathrm{~cm}$ from the spectrometer slit in front of which stood the glass absorption cell. This great distance reduces the radiation considerably, so that no high accuracy can be claimed for the measurements in the violet. Furthermore, the visible spectrum is too narrow (a fluorite prism was used), so that for quantitative work of the highest precision the absorption in the visible will have to be determined anew, using a larger dispersion. For this region of the spectrum the spectrophotometer would be better than the linear bolometer. The glass absorption cell was $2.1 \mathrm{~cm}$ in thickness, the glass walls being $2 \mathrm{~mm}$ in thickness. The saturated solutions mentioned in this paper were made at $25^{\circ} \mathrm{C}$.

Manganous sulphate, $\mathrm{MnSO}_{4}$.-

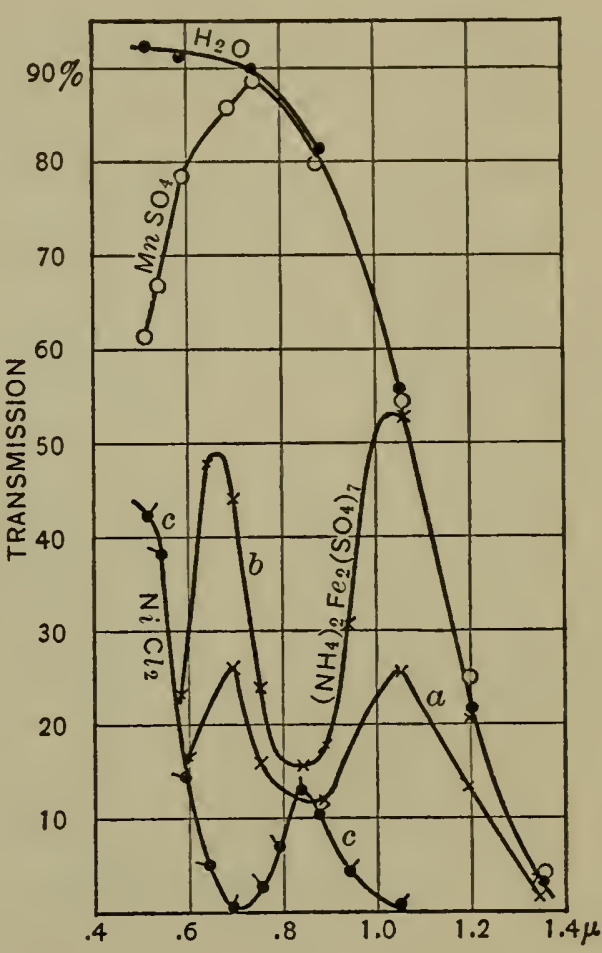

Fig. 15.-Water; Manganous Sulphate; Nickel Chloride; A mmonium-Iron Alum The transmission curve ( . . . ) of

a saturated solution of manganous sulphate is given in figure ${ }_{5}$. Beyond $0.8 \mu$ the transmission coincides with that of the same thickness of pure water. Potassium dichromate. $K_{2} C_{r} O_{7}$, absorbs the violet and is transparent in the infra-red.

Ammonium-iron alum, $\left(\mathrm{NH}_{4}\right)_{2} \mathrm{Fe}_{2}\left(\mathrm{SO}_{4}\right)_{7}$. - In figure I $_{5}$, curve $a$ gives the transmission of a saturated solution (slightly acid), and curve $b$ gives the transmission of a highly concentrated solution of

${ }^{32}$ Publication No. 97, Carnegie Institution of Washington; I908. 
ammonium-iron alum. There is a large absorption band at $0.85 \mu$. Beyond $\mathrm{I} \mu$ the transmission of the concentrated solution is as high as that of the same thickness of pure water. The transmission curve of ammonium-iron alum published by Nichols ${ }^{33}$ does not show the band at $0.85 \mu$.

Nickel chloride, $\mathrm{NiCl}_{2}$. - The saturated solution transmitted but little radiation. The solution was therefore diluted to three times

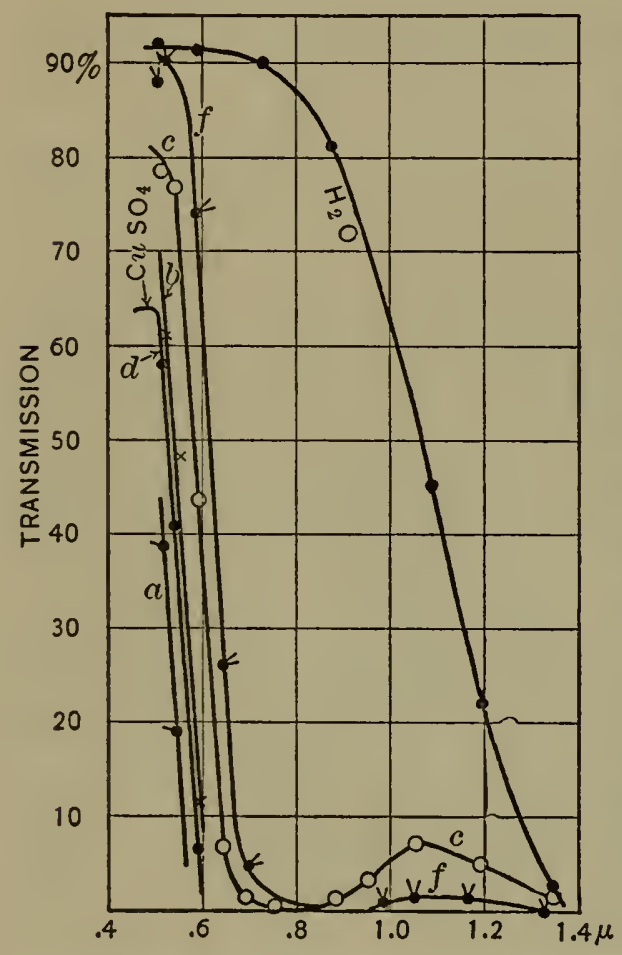

Fig. 16.-Copper; Acetate $(a, b, c)$, Sulphate $(d)$, and Potassium Chloride $(f)$ its volume. The transmission of the latter solution is given in curve $c$, figure 15 . The transmission is less than 50 per cent in the green, while at $0.85 \mu$ there is an appreciable transmission amounting to i 3 per cent at the maximum.

Nickel nitrate was also examined, and a similar (high) transmission band was found at $0.85 \mu$. It therefore appears that these nickel salts are not suitable for absorption screens.

Copper sulphate, $\mathrm{CuSO}_{4}+{ }_{5} \mathrm{H}_{2} \mathrm{O}$.The transmission curve ( . . .) of a saturated solution of copper sulphate is given in curve $d$, figure $\mathrm{I} 6$. There is complete opacity beyond $0.6 \mu$.

The transmission is high in the blue, so that this substance is suitable for eliminating all but the blue light.

Copper potassium chloride, $\mathrm{CuCl}_{2}-2 \mathrm{KCl}+2 \mathrm{H}_{2} \mathrm{O}$. -The transmission of a 2.5 per cent solution of copper potassium chloride is given in curve $f$, figure 16 . Its transmission is not much greater than cupric chloride in the visible while at I.I $\mu$ it transmits 1.2 per cent against 0.67 per cent for the same concentration of cupric chloride. See figure $\mathrm{x} 7$.

Copper acetate, $\mathrm{Cu}\left(\mathrm{C}_{2} \mathrm{H}_{3} \mathrm{O}_{2}\right)_{2}$. -The transmission of a 5 per cent (2 $\mathrm{g}$ in $38 \mathrm{cc}_{2} \mathrm{O}, 3$ drops acetic acid) solution of copper acetate

${ }^{33}$ E. F. Nichols: Phys. Rev., 1, p. I; 1896. See also Carnegie Publication No. 97, p. $50 ; 1908$. 
is given in curve $a$, figure 16 . Curve $b$ gives the transmission of a 2.5 per cent solution and curve $c$ gives the transmission of a I per cent solution of copper acetate. The latter transmits too much infra-red radiation (about 7 per cent at $\mathrm{r} .05 \mu$ ) to be of great use as an absorption screen.

Cupric chloride, $\mathrm{CuCl}_{2}+2 \mathrm{H}_{2} \mathrm{O}$. - The most suitable screen for absorbing the infra-red, and at the same time having a high transmission in the yellowish green and in the blue is cupric chloride. This is illustrated in the various curves given in figure 17 . Curve $I$ gives the transmission of a Io per cent solution ( $2 \mathrm{gr} . \mathrm{CuCl}_{2}+$ I $8 \mathrm{cc} \mathrm{H}_{2} \mathrm{O}+2$ drops of 20 per cent $\mathrm{HCl}$ ) of cupric chloride. Curve 2 gives the transmission of a Io per cent solution containing $0.5 \mathrm{cc}$ of 20 per cent $\mathrm{HCl}$. This shows that the addition of acid has no effect on the infra-red, and but little effect in the visible. Curve 3 gives the transmission of a 5 per cent solution; curve 4 a 2.5 per cent solution, and curve $5 \mathrm{a}$ I per cent solution. The latter transmits a very considerable amount of infra-red radiation, hence unsuitable as a screen. The 2.5 per cent solution, curve 4 , transmits 0.0067 at I.I $\mu$ (in the dotted curve 4 at I.I $\mu$ the ordinates are multiplied by 20 ) which is negligible. A further examination was made of a very accurately prepared 2 per cent solution. It transmitted 88 per cent at $0.54 \mu, 67$ per cent at $0.589 \mu, 20$ per cent at $0.646 \mu$, and 0.69 per cent at $\operatorname{x.1} \mu$. It may therefore be assumed that a 2 -cm layer of a 2 per cent solution $\left(2 \mathrm{~g} \mathrm{CuCl}_{2}\right.$ in $98 \mathrm{cc} \mathrm{H}_{2} \mathrm{O}$ ) of cupric chloride absorbs all the infra-red beyond $0.67 \mu$ and transmits from 80 to 85 per cent at $0.5 \mu$ and about 70 per cent at $0.58 \mu$, which is in the region of the yellow mercury line.

In separating the yellow from the green or blue lines it is, of course, necessary to combine the absorption cell of cupric chloride with a monochromatic red, green, or blue (for the blue, the copper sulphate solution may be sufficient) glass. This, of course, reduces the intensity still further, but it will hardly fall below 50 per cent of its original value. When we consider that the sensitivity of a bolometer is closely proportional to the square root of the surface and that a linear bolometer is never larger than I by $15 \mathrm{~mm}$ (usually $0.5 \times$ IO $\mathrm{mm}$ ), while a surface bolo- 


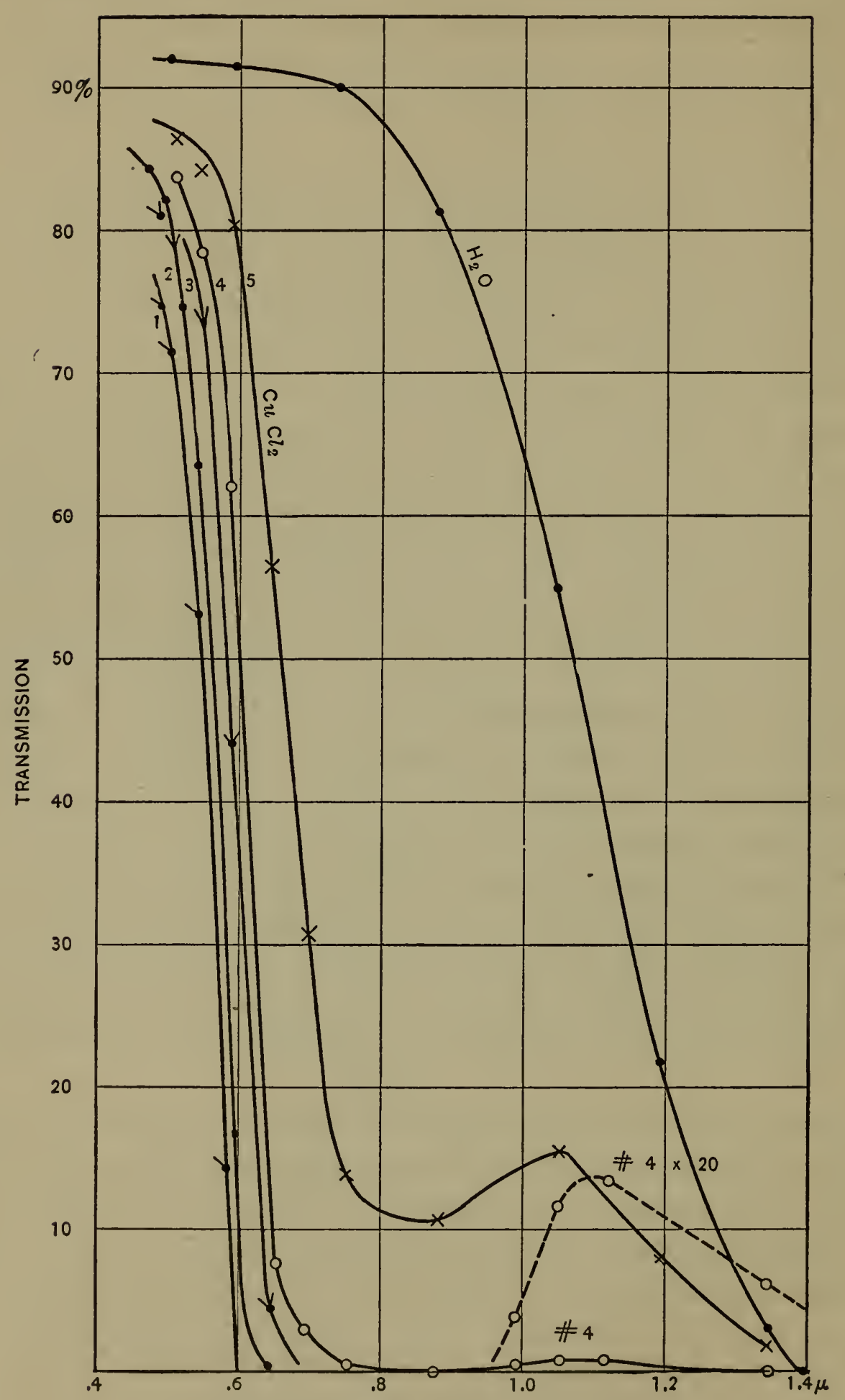

Fig. 17.-Cupric Chloride, $\mathrm{CuCl}_{2}+2 \mathrm{H}_{2} \mathrm{O}$ 
meter is at least $40 \times 50 \mathrm{~mm}$, the advantage of the latter combined with an absorption cell is apparent. Take, for example, the determination of the mechanical equivalent of light, in connection with which the present question of absorption screens was undertaken. The determination of the mechanical equivalent of light requires an accurate measurement of the candlepower of the light used and its value in energy units. The determination of the candlepower is an easy matter. The determination of the energy equivalent is beset with such difficulties that measurements made with the best instruments (absolute bolometers and calorimeters) for measuring radiation in absolute units differ by 5 to ro per cent. Until some of these radiometric difficulties have been overcome it is, of course, futile to discuss the various proposals of a unit of light based upon its energy equivalent in absolute measure.

\section{SPECTRAL LINES SUITABLE FOR INFRA-RED REFER- ENCE STANDARDS}

If the optical constants of the material used are unknown it is usually more convenient to calibrate a prism (or a wire grating) by picking out sharply defined emission or absorption bands, such as those noticed in sylvite on a previous page. The accuracy attainable in determining the position of the maximum of such a reference standard is of the order of $0.02 \mu$, depending upon the experience of the observer.

It is beyond the scope of the present note to discuss the various instruments, and the most suitable prisms and standard lines to be used in spectroradiometry, that part being left for some future time. Reference standards must be easily obtainable, otherwise it is quicker to compute the calibration curve from the refractive indices and the angle of the prism. In his experiments on residual rays, lying between $8 \mu$ and $60 \mu$, the writer calibrated ${ }^{34}$ his wire gratings by means of the residual rays reflected from quartz fluorite, mica, and rock salt.

As a fiducial line the writer uses the yellow helium line, $\lambda=$ $0.5876 \mu$, as obtained in an ordinary vacuum tube, and any other

${ }^{34}$ Carnegie Publication No. 65, p. 25, Ig08. 
point in the infra-red is read from the spectrometer circle. For example, the sharp absorption band of sylvite at $3.18 \mu$, using a $60^{\circ}$ fluorite prism, is found at a distance of $I^{\circ} 25^{\prime}$ from the yellow helium line.

The standard lines may be produced by emission of incandescent solids and gases; by transmission through solids, liquids, or gases; and by reflection from plane, highly polished surfaces of solids or the surface of a liquid.

The radiation from an ordinary Bunsen burner furnishes an intense, sharply defined emission band at $4.40 \mu$.

Sharp bands of selective emission of oxides in the form of solid rods, heated electrically or in the form of powders upon a heater, are easily produced. ${ }^{35}$

Zirconium oxide with very sharp maxima at $2.83 \mu$ and $4.3 \mu$, feldspar with sharp maxima at $2.88 \mu$ and $4.5 \mu$, and talc with a group of maxima at $2.42 \mu, 2.75 \mu$, and $3.35 \mu$, respectively, are excellent standards of this type. Salts of various metals in the arc of cored carbon electrodes give strong emission bands ${ }^{36}$ near the visible spectrum. This type of radiator is not easily operated. The mercury arc is better adapted, and it has strong maxima at I.or $4 \mu$ and I.I $29 \mu$, respectively. Helium gas (vacuum tube) has maxima at $\mathrm{I} .08 \mu$ and $2.06 \mu$, observable with delicate instruments.

Transmission spectra are the most easily observed, as noticed on a previous page, and the number of absorption bands suitable reference standards is too numerous to mention. Without elaborate accessory apparatus a rock-salt or a fluorite prism can be calibrated by resorting entirely to transmission spectra. For example, a film of water between fluorite plates, or a plate of selenite, gives the bands at $\mathrm{I} .5,2,3,4.75$, and $6.08 \mu$. A film of collodium has sharp bands at $6.05 \mu$ and $7.85 \mu$. A better example ${ }^{37}$ and one that would cause less confusion is potassium dichromate with a single, very intense absorption maximum at $5.4 \mu$, or potassium chlorate which has a similar maximum at $5.25 \mu$. Sylvite has a pair of very sharp absorption bands at $3.18 \mu$ and $7.08 \mu$, respectively. Oleic acid has strong absorption bands at $5.86 \mu$,

${ }^{35}$ This bulletin, 5, p. I 59; 6, p. 30 I, I910.

${ }^{36}$ See Carnegie Publication 35, r905. This bulletin, 2, p. 457, 1907.

${ }^{37}$ Carnegie Publication 65, p. $57,1908$. 
I0. $8 \mu$, and $\mathrm{I} 4 \mu$. Carbon tetrachloride has a very large absorption band at $13 \mu$, which can not be confused with any of the small bands which are present.

The reflecting power being so low in all substances yet examined, except quartz and selenite, unless one has very sensitive measuring instruments, there is little hope of success in working out a calibration by means of bands of selective reflection.

Some gases, e. g., $\mathrm{SO}_{2}$ and $\mathrm{CO}_{2}$, have sharp absorption bands suitable for calibration work, but the accessory apparatus is not so easily manipulated as in the transmission of solids and liquids and in the emission from oxides.

WASHINGTON, May i6, igir. 